OPEN ACCESS

Edited by:

Takanori So,

University of Toyama, Japan

Reviewed by:

Alexander Akhmedov,

University of Zurich, Switzerland

Simon Kraler,

University of Zurich, Switzerland

*Correspondence:

Dennis Wolf

dennis.wol@uniklinik-freiburg.de

Specialty section:

This article was submitted to

Atherosclerosis and Vascular

Medicine

a section of the journa

Frontiers in Cardiovascular Medicine

Received: 01 December 2021

Accepted: 27 January 2022

Published: 17 February 2022

Citation:

Gissler MC, Stachon P, Wolf D and Marchini T (2022) The Role of Tumor Necrosis Factor Associated Factors (TRAFs) in Vascular Inflammation and

Atherosclerosis.

Front. Cardiovasc. Med. 9:826630

doi: $10.3389 /$ fcvm.2022.826630

\section{The Role of Tumor Necrosis Factor Associated Factors (TRAFs) in Vascular Inflammation and Atherosclerosis}

\author{
Mark Colin Gissler ${ }^{1,2}$, Peter Stachon ${ }^{1}$, Dennis Wolf ${ }^{1,2 *}$ and Timoteo Marchini ${ }^{1,2,3}$ \\ ${ }^{1}$ Cardiology and Angiology, Medical Center, University of Freiburg, Freiburg im Breisgau, Germany, ${ }^{2}$ Faculty of Medicine, \\ University of Freiburg, Freiburg im Breisgau, Germany, ${ }^{3}$ Universidad de Buenos Aires, CONICET, Instituto de Bioquímica y \\ Medicina Molecular (IBIMOL), Facultad de Farmacia y Bioquímica, Buenos Aires, Argentina
}

TNF receptor associated factors (TRAFs) represent a family of cytoplasmic signaling adaptor proteins that regulate, bundle, and transduce inflammatory signals downstream of TNF- (TNF-Rs), interleukin (IL)-1-, Toll-like- (TLRs), and IL-17 receptors. TRAFs play a pivotal role in regulating cell survival and immune cell function and are fundamental regulators of acute and chronic inflammation. Lately, the inhibition of inflammation by anti-cytokine therapy has emerged as novel treatment strategy in patients with atherosclerosis. Likewise, growing evidence from preclinical experiments proposes TRAFs as potent modulators of inflammation in atherosclerosis and vascular inflammation. Yet, TRAFs show a highly complex interplay between different TRAF-family members with partially opposing and overlapping functions that are determined by the level of cellular expression, concomitant signaling events, and the context of the disease. Therefore, inhibition of specific TRAFs may be beneficial in one condition and harmful in others. Here, we carefully discuss the cellular expression and signaling events of TRAFs and evaluate their role in vascular inflammation and atherosclerosis. We also highlight metabolic effects of TRAFs and discuss the development of TRAF-based therapeutics in the future.

Keywords: TRAF, atherosclerosis, immunity, inflammation, TNF, signaling

\section{ATHEROSCLEROSIS IS A CHRONIC INFLAMMATORY DISEASE OF ARTERIES}

Atherosclerosis is a disease of medium- to large-sized arteries that leads to the build-up of vessel occluding atherosclerotic plaques. Endothelial erosion and plaque rupture represent frequent and fatal complications of atherosclerosis that may lead to the formation of arterial thrombi, vessel occlusion, and subsequent tissue ischemia $(1,2)$. The prevalence of diseases caused by atherosclerosis, including coronary heart disease, stroke, and peripheral arterial occlusive disease, continues to rise and doubled from 271 million in 1990 to 523 million in 2019 (3, 4). The accumulation of low-density lipoprotein (LDL) cholesterol in the subintimal space of arteries triggered by cardiovascular risk factors, such as hypertension and diabetes mellitus, is the major culprit of atherosclerotic disease. Beyond the passive accumulation of LDL in the atherosclerotic plaque and its uptake by tissue-resident macrophages that fuels plaque growth, cumulating 
evidence of numerous preclinical and clinical studies have stablished that atherosclerosis is a chronic inflammatory and immune-driven disease of the arterial wall (5). This response involves stromal cells, such as endothelial cells (EC) and smooth muscle cells (SMC), and cells of the innate and adaptive immune system. Recent evidence suggests that a part of the immune response in atherosclerosis is caused by autoimmunity against LDL and Apolipoprotein B $(6,7)$. Immune cells accumulate in the subintimal space of atherosclerotic arteries and interact with stromal cells by direct cellular contact and cytokines $(8,9)$. It is now established that inflammation is a local and systemic process that promotes atherosclerosis at all stages, from initial endothelial dysfunction to thrombotic complications of acute plaque rupture (10). Therapeutic inhibition of inflammation has the potential to prevent atherosclerosis progression and improve cardiovascular outcomes, as recently demonstrated by a neutralizing antibody against the pro-inflammatory master cytokine interleukin (IL)- $1 \beta$ by canakinumab (11), the proinflammatory cytokine IL-6 (12), and by colchicine that has broad anti-inflammatory properties $(13,14)$. Neutralization of other pro-inflammatory cytokines, such as of TNF- $\alpha$ and IL17 , revealed inconsistent effects on cardiovascular end-points (15) or worsened cardiovascular risk factors as exemplified by the increased risk for hypertension during anti-TNF therapy of rheumatoid arthritis (16). In addition, potential side-effects of live-long immune-modulating therapy, such as infection, have not yet been systematically evaluated albeit first safety signals from canakinumab and colchicine trials were promising (17, 18). It is therefore instrumental to define alternative therapeutic targets that are confined to atherosclerosis-relevant cell types and broadly regulate inflammatory signaling cascades without the risk of severe immunosuppression. Mostly preclinical evidence has suggested that TRAFs may represent such inflammatory targets.

\section{PRO-INFLAMMATORY AND CELLULAR NETWORKS IN ATHEROSCLEROTIC DISEASE}

It is now well-established that inflammatory signaling cascades are potent modulators of atherosclerosis (19). Besides their clinical use as biomarkers (20), several cytokines have been shown to orchestrate the inflammatory response in the atherosclerotic plaque, such as TNF- $\alpha$, IL-1 $\beta$ IL-6, and IL-12 (21). Cytokines are soluble factors that are locally produced in atherosclerotic plaques and in remote organs, mostly, yet not exclusively, by immune cells (22). They circulate through the blood stream and modulate immune mechanisms in a plethora of stromal and immune cells in the plaque and cardiometabolic key organs. Distinct outcomes of cytokine signaling pathways are determined by their specific binding to a range of receptors with cell type-specific expression, and partially synergistic and antagonistic functions. Cytokines are involved in all stages of atherosclerotic disease, from initial endothelial dysfunction to pro-thrombotic events (21). Consistently, it has been established that a therapeutic modulation of some pro-inflammatory master cytokines and their receptors may efficiently interfere with atherosclerosis development in preclinical mouse models. CD40L, TNF- $\alpha$, and IL-1 $\beta$ have been extensively evaluated in experimental atherosclerosis (23-25) and the development of underlying cardiometabolic risk factors $(26,27)$. One relevant limitation of targeting single receptor-ligand pairs, however, is their fundamental role in host-defense, regeneration, and other physiological processes, such as haemostasis. For instance, mice genetically deficient for CD40L or wild type mice treated with a blocking anti-CD40L antibody are protected from atherosclerosis (28). However, clinical treatment with a neutralizing antiCD40L antibody in patients with Systemic Lupus Erythematosus has failed due to a higher rate of thrombotic complications (29). Likewise, inhibition of TNF- $\alpha$ reduces experimental atherosclerosis (30), but long term inhibition of TNF- $\alpha$ in patients increases the risk for opportunistic infections and nonmelanoma skin cancers (31). It has therefore been proposed that targeting inflammatory signaling cascades downstream of several pro-inflammatory receptors may overcome some of these limitations.

\section{TRAFS ARE INTRACELLULAR ADAPTER PROTEINS THAT REGULATE INFLAMMATORY SIGNALING}

TNF receptor associated factors (TRAFs) are a family of cytoplasmic molecules that transduce, regulate, and bundle receptor-mediated signaling by distinct classes of cell-surface receptors that can activate or inhibit downstream signaling pathways mostly by canonical and non-canonical Nuclear Factor kappa B (NF- $\kappa$ B) signaling (32). TRAFs associate with TNF receptors (TNFRs), interleukin 1 receptor (IL-1R), Tolllike receptors (TLRs), RIG-I-like receptors (RLRs), NOD-like receptors (NLRs), and receptors for IL-2, IL-17, IFN, and TGF$\beta$ (33-37) (Table 1). The biological role of TRAFs is to regulate cell survival, immunity, and inflammation. To this date, seven different TRAFs, TRAF1 to 7 , have been described $(32,38)$. Because of their ability to modulate downstream signaling of the above mentioned pro-inflammatory receptors, and their broad expression patterns among immune and stromal cell types, TRAFs have gained increasing attention as central inflammatory hubs that may become accessible to a therapeutic modulation of inflammatory disease $(39,40)$.

Members of the TRAF family are structurally homologous (Figure 1). All TRAFs except for TRAF7 share a common domain of 180 amino acids at the C-terminal end, the "TRAF domain," which is required for oligomerization of TRAF proteins and for the interaction with upstream receptors and downstream effector proteins (41). The TRAF domain consists of two subdomains: a variable coiled-coil TRAF-N domain and a highly conserved TRAF-C domain formed by seven to eight anti-parallel $\beta$-strands, known as the Meprin or the TRAF-C homology (MATH) domain (42). The TRAF-C subdomain allows TRAF molecules to form homo or heterodimers, and to recognize cytoplasmic tails of associated receptors. At the N-terminal end, a flexible $\alpha$-helical structure mediates downstream signaling 
TABLE 1 | TRAFs-associated receptor and ligand pairs.

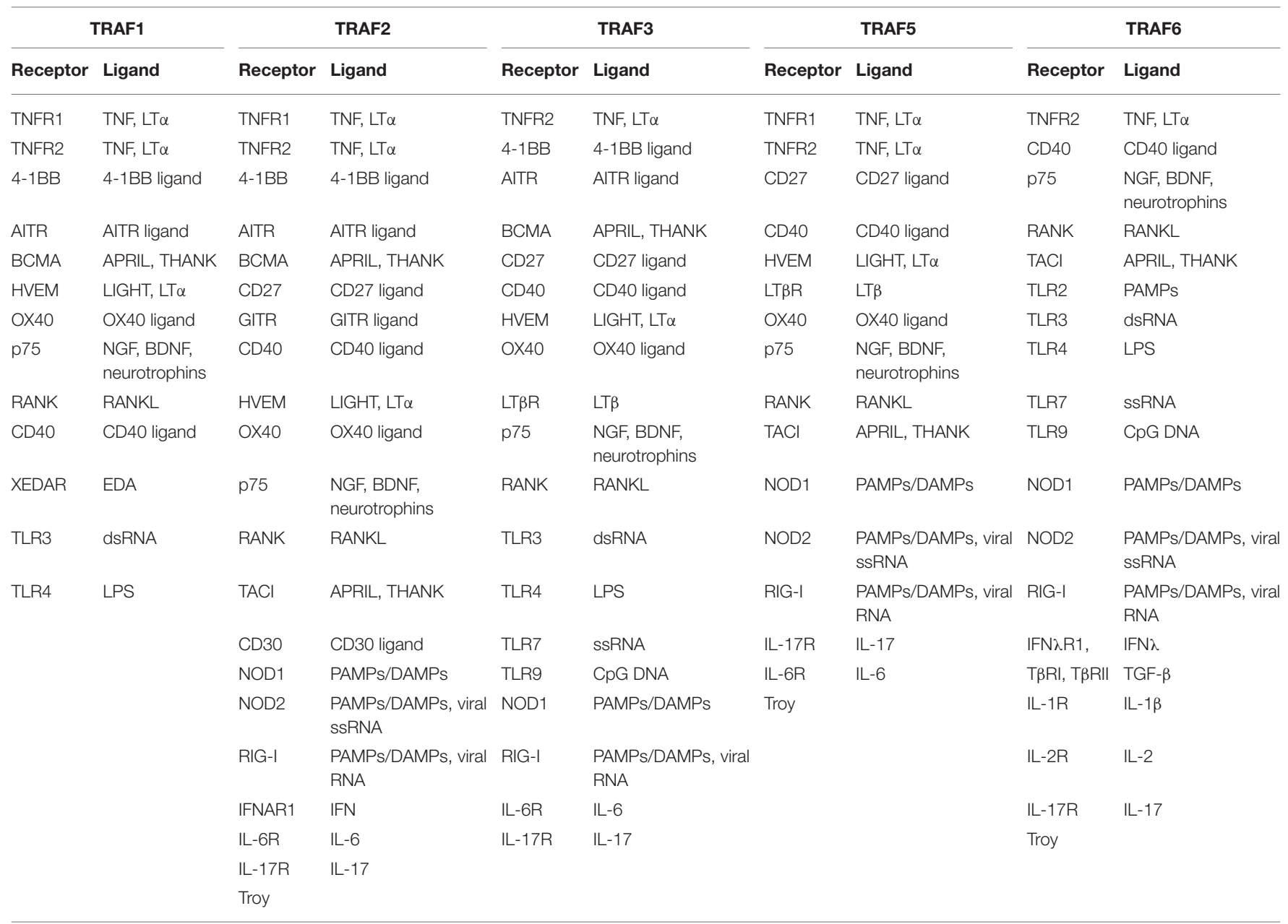

TRAFS-associated receptors are shown in the left column while ligands for TRAFs-associated receptors are shown in the right column.

and the recruitment of effector enzymes by Zinc- and RINGfinger motifs (43). The N-terminal "Really Interesting New Gene" (RING) domain represents the second structurally homologous elements shared by most TRAF members, except for TRAF1. It allows TRAFs to act as an E3 ubiquitin ligase in addition to their scaffolding function (44). Following receptor activation, TRAFs either bind directly to the cytoplasmic tail of the receptor via the TRAF-C domain or indirectly via other adapter proteins such as TNFR type 1 Associated Death Domain (TRADD), Myeloid Differentiation primary response gene 88 (MyD88), or IL-1R Associated Kinase (IRAK). These intermediate signaling adaptors regulate the activation of different kinases including Mitogen Activated Protein Kinase (MAPK) such as JNK, p38, ERK-1/2 (45), and IКB Kinase (IKK). As a result, TRAFs can activate or suppress transcription factor $\mathrm{NF}-\kappa \mathrm{B}$ and regulate proinflammatory cytokine-, chemokine-, and adhesion molecule expression $(46,47)$. In addition, TRAFs can activate Apoptosis Protein 1 (AP-1), a transcription factor that promotes cellular response to stress (48). Interaction with cellular Inhibitors of Apoptosis Proteins (cIAP1/2) during NOD-like receptor signaling (49) regulates cell survival. Notably, TRAF molecules can interact in homo- or heterooligomers of TRAF family members to increase their avidity and form receptor signaling complexes (40). Importantly, different TRAFs interact with each other to amplify or inhibit distinct inflammatory signaling pathways and may compensate the function of other TRAFs. Given that each TRAF is differentially regulated, interacts with distinct receptors, and activates a variety of downstream signaling pathways, TRAFs represent individual branching points in inflammatory signaling cascades (Figure 2). Different inflammatory stimuli can converge in one TRAF; on the other hand, one inflammatory signal can be divided into different downstream signals through multiple TRAFs (43). This can be exemplified by IL-17R signaling: Upon binding of IL-17, heteromeric IL-17RA and IL-17RC recruit TRAF2, TRAF5, and TRAF6 via the adaptor protein Act1. While TRAF2 and TRAF5 induce activation of MAPKs, TRAF6 mediates activation of NF$\kappa \mathrm{B} 1, \mathrm{IkB} \varsigma, \mathrm{C} / \mathrm{EBP} \beta$, and $\mathrm{C} / \mathrm{EBP} \delta$. TRAF3 and TRAF4, on the other hand, inhibit IL-17 signaling by interacting with IL-17RA and IL-17RC or Act1, respectively (40). 


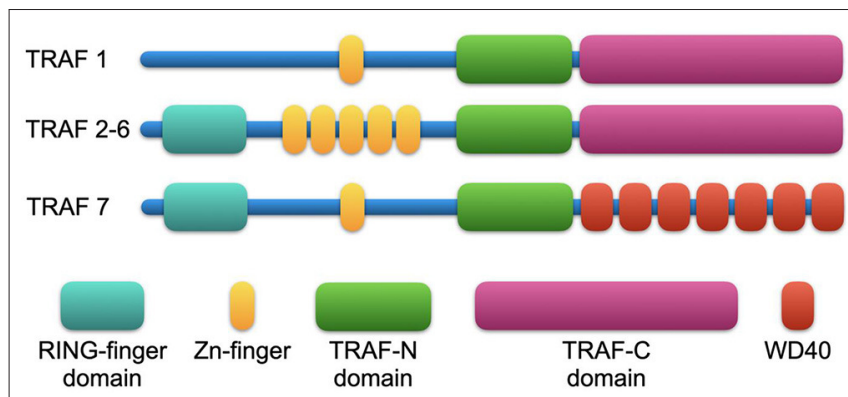

FIGURE 1 | Structural features of TRAF proteins. All TRAF family members (except for TRAF7) share a common domain of 180 amino acids at the C-terminal end, the "TRAF domain," which consists of two subdomains: a variable coiled-coil TRAF-N domain and a highly conserved TRAF-C domain, known as the Meprin or the TRAF-C homology (MATH) domain, that is required for oligomerization of TRAF proteins and for the interaction with upstream receptors and downstream effector proteins. At the N-terminal end, a Really Interesting New Gene (RING) domain hosts TRAFs E3 ubiquitin ligase function (except for TRAF1). TRAFs also recruit effector proteins by a variable number of Zn-finger domains: TRAF1 and TRAF7 have one Zn-finger domain; TRAF2, 3, 5, and 6 have five $Z n$-finger domains; and TRAF4 has seven $Z n$-finger domains. In TRAF7, the TRAF-C domain is replaced by WD40-repeats.

\section{EXPRESSION OF TRAFS IN ATHEROSCLEROSIS-RELEVANT CELL TYPES}

Immune, endothelial, and smooth muscle cells are the most abundant cell types that build the microarchitecture of atherosclerotic plaques (50). TRAFs have distinct expression profiles across these cell types and other stromal cell types: In the human transcriptome, expression of TRAF1 and TRAF5 is mostly confined to immune cells with the strongest expression in monocytes and lymphocytes, respectively (Figure 3A). Other TRAFs, such as TRAF2, TRAF6, and TRAF7, are ubiquitously expressed in stromal and immune cells. TRAF3 is mostly expressed in glial cells, neuronal cells, $\mathrm{T}$ and $\mathrm{B}$ cells; TRAF4 in epithelial and trophoblast cells (51). Expression of mRNAs coding for TRAF4, TRAF5, and TRAF7 can be detected in ECs, SMC, and adipocytes (Figure 3B). There is also a considerable variation among different immune cell types: TRAF1, TRAF4, and TRAF5 are the most expressed TRAFs in human T cells, while B cells express high levels of TRAF3, TRAF4, and TRAF5 but not of TRAF1. In human monocytes, TRAF1 is strongly expressed and shows the highest relative expression of all cell types available in the human protein atlas. Human dendritic cells (DCs) contain most TRAF4 transcripts compared to all tested immune cell types, while NK cells are generally only weak TRAFexpressors. Human expression patterns are distinct to mouse transcriptomic atlases, such as the Immunological Genome Project (ImmGen) (52), and suggest differential functional repertoires in mice and humans (Figure 3C). While these findings inferred from TRAF mRNA expression suggest clear patterns of cell type specificities and function, it is important to note that gene expression may not ultimately predict protein expression, post-translational modification, or function. This is highlighted by numerous reports demonstrating functional protein expression of TRAFs in B cells (53), T cells (54), DCs (55), neutrophils (56), macrophages (57), platelets (58), adipocytes (59), SMC (57), and EC (60), even if mRNAs are expressed at only low levels in resting cells. In addition, expression of TRAFs in macrophages, SMC, and EC (57) increases during inflammation. Whether tissue expression of TRAFs is modulated at atherosclerotic predilection sites, such as arterial branching points, or parts of the vasculature that are protected from atherosclerosis in humans, such as the internal thoracic artery (ITA), remains to be investigated (61). In the following sections, we will discuss expression, signaling networks (Figure 2), and functional roles of TRAFs in vascular inflammation and associated pathologies (Figure 4).

\section{TRAF1}

Expression of TRAF1 (46 kDa) is mainly regulated by NF- $\mathrm{KB}$ activation (62). While most resting cells lack TRAF1 protein expression, TRAF1 is strongly upregulated in activated immune cells, mostly in mononuclear cells and lymphocytes, as well as in EC and SMC from atherosclerotic lesions $(57,63,64)$. In contrast to other TRAFs, TRAF1 lacks a RING-finger domain and expresses only one Zinc-finger domain (32). Intracellular signaling proteins such as TRAF-Interacting Protein (TRIP), Receptor-Interacting Protein (RIP), caspase 8, members of the cellular inhibitors of apoptosis (cIAP) family, as well as TRAF2, interact with TRAF1 $(41,65-68)$. TRAF1 and TRAF2 were the first TRAFs to be characterized, notably by their interaction with TNF receptor 2 (TNFR2) $(69,70)$.

TRAF1 contributes to signaling events by TNF-receptor superfamily members such as TNFR1, TNFR2, or CD40, and inhibits TLR-induced TRIFF signaling (71). Members of the TNFR superfamily stimulate cell survival by the activation of canonical NF- $\mathrm{KB}$ signaling and pro-inflammatory MAPK pathways (40). TRAF1 supports canonical NF- $\mathrm{KB}$ signaling events from TNFR1, TNFR2, CD40, 4-1BB, and LMP-1 by forming heterotrimers with TRAF2 and possibly through stabilizing TRAF2 by inhibiting its degradation by proteasomes (72-74). The complex of TRAF1 and TRAF2 is part of the E3 ubiquitin protein ligase and positively signals TNF- $\alpha /$ TNFR2 -dependent NF- $\kappa \mathrm{B}$ and MAPK8/JNK activation and proinflammatory gene expression, which is considered a prosurvival event $(75,76)$. TRAF1, together with TRAF2 and cIAPs, supresses apoptosis (77), which is also supported by the observation that TRAF1 is instrumental for antigenspecific $\mathrm{CD}^{+} \mathrm{T}$ cell responses during HIV and influenza virus infection, partially by promoting $\mathrm{T}$ cell survival and memory $(62,78)$. The absence of TRAF1, thus, impairs NF-кB signaling and favors the accumulation of pro-apoptotic signals in the cell, while transgenic over-expression of TRAF1 supports cell survival $(54,79)$. In hepatic ischemia/reperfusion injury, TRAF1-deficiency is protective through an inhibition of NF- $\mathrm{BB}$ mediated inflammation (80). The proposed pro-inflammatory role of TRAF1 has also been substantiated by reports showing attenuated lung inflammation after lipopolysaccharide (LPS) challenge in TRAF1-deficient mice (81). Taken together, these results argue for a pro-inflammatory and anti-apoptotic function of TRAF1. Other findings, however, have yielded contrasting 


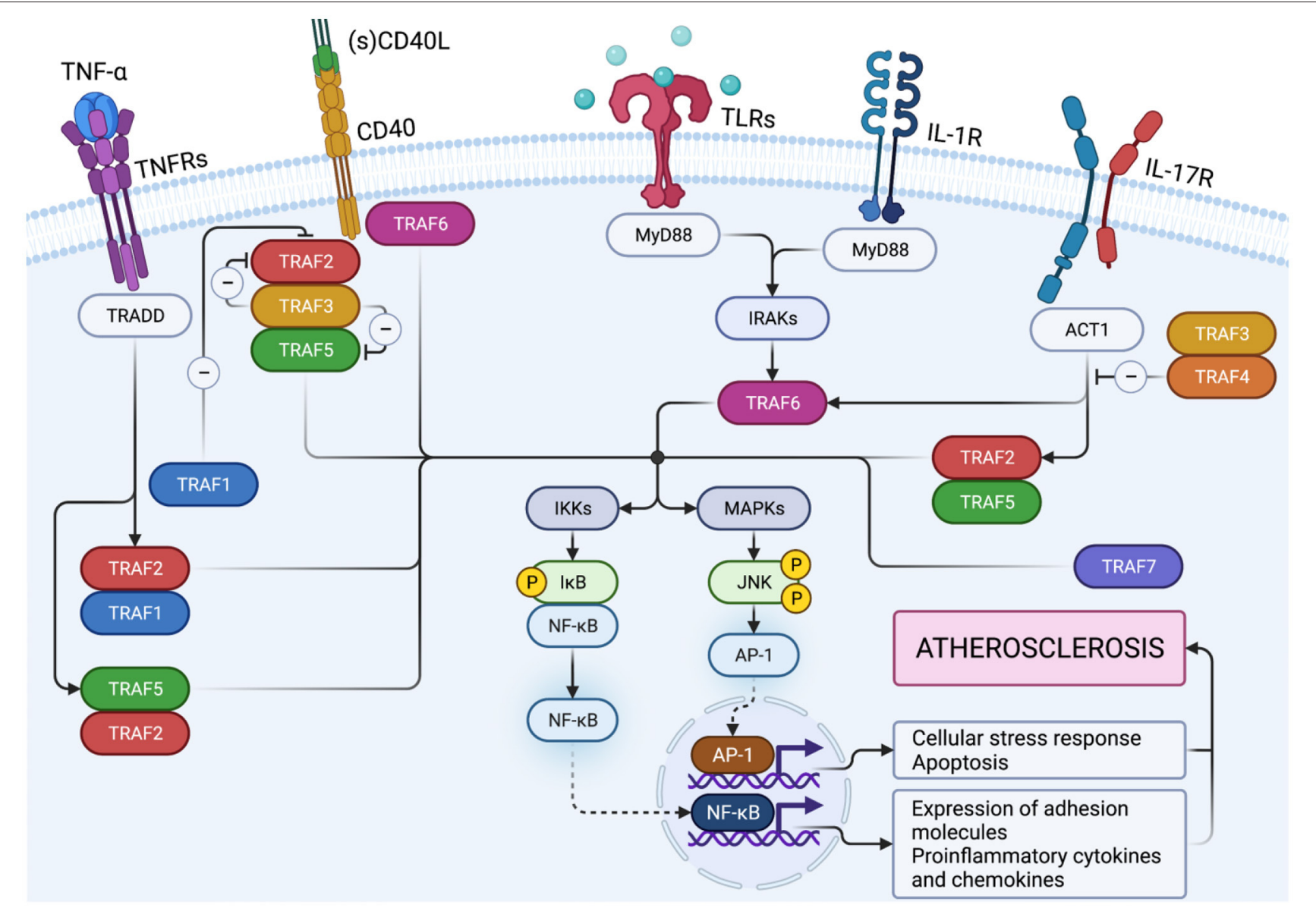

FIGURE 2 | TNF-receptor associated factors (TRAFs) link proximal receptor ligation and distal signaling pathways. Upon TNF-binding, TNFR1 activates inflammatory signaling pathways via TRAF1, TRAF2, and TRAF5. CD40 ligation induces canonical and non-canonical NF- $\mathrm{kB}$ activation by TRAF2/5 and canonical NF- $\mathrm{kB}$ activation by TRAF6. TRAF3 inhibits NF-kB activation mediated by TRAF2/5 but does not interfere with transcriptional activity of TRAF6-mediated NF-kB. TRAF1 inactivates TRAF2 by direct binding and is considered an inhibitory TRAF. Activation of TLRs and IL-1R can promote MyD88 dependent TRAF6 activity. Following binding of IL-17, heteromeric IL-17RA and IL-17RC recruit TRAF2, TRAF5, and TRAF6 via the adaptor protein Act1 to induce activation of downstream signaling pathways. TRAF3 and TRAF4 on the other hand, inhibit IL-17 signaling by interaction with IL-17R or Act1, respectively. Created with BioRender.com.

results that question a merely pro-inflammatory role of TRAF1. First, TRAF1-deficiency unexpectedly induced a hyperproliferative phenotype in $\mathrm{T}$ cells after TNF/TNFR2-dependent stimulation in one report (82), suggesting TRAF1 is a negative regulator of TNFR-signaling. A possible explanation is that TRAF1 can restrain non-canonical NF- $\kappa B$ signaling (83) and T cell proliferation (84). Besides its positive regulation of NF- $\kappa B$ signaling, TRAF1 may also limit NF- $\mathrm{KB}$ activation by several less frequent mechanisms $(85,86)$. In addition, TRAF1 can dampen TLR/NLR-dependent activation of NF- $\kappa B$ by sequestering the linear ubiquitin assembly complex (LUBAC). This process seems to be independent of TRAF2 and TNFRs (87). Notably, TRAF1deficient mice are more susceptible to an LPS-induced septic shock (87). A single nucleotide polymorphism (SNP) at the C5-locus of TRAF1 is associated with rheumatoid arthritis in humans $(88,89)$. Patients with a homozygous TRAF1/C5 rs3761847 GG locus show increased mortality in sepsis and malignancies (90), establishing a clinical association with hyperinflammation. In addition to its anti-inflammatory properties in TLR signaling, TRAF1 has been reported to disrupt the interaction between TRAF2 and CD40, leading to an attenuation of NF- $\kappa \mathrm{B}$ activation (76). In vivo, TRAF1-deficient mice showed an increased responsiveness to TNF-induced skin necrosis. In this study, the authors accounted TRAF1 as a negative regulator of TRAF2-depending NF- $\kappa B$ activation (82). Down the same line, intratracheal TNF- $\alpha$ stimulation in TRAF1 ${ }^{-/-}$mice exacerbates TNFR1-dependent liver injury (91). In conclusion, TRAF1 seems to exert differential and partially opposing roles in inflammation and apoptosis, likely caused by cell type and receptor-specificity and the precise signaling context.

\section{Role of TRAF1 in Vascular Inflammation}

TRAF1 is overexpressed in murine atherosclerotic lesions and in neointima formation after arterial injury $(57,92)$. Atherosclerosis-prone LDLR-deficient mice with a genetic deficiency of TRAF1 develop significantly smaller atherosclerotic lesions after 8 or 18 weeks of high cholesterol diet, suggesting a pro-atherogenic role of TRAF1 (60). This decrease of de 
A

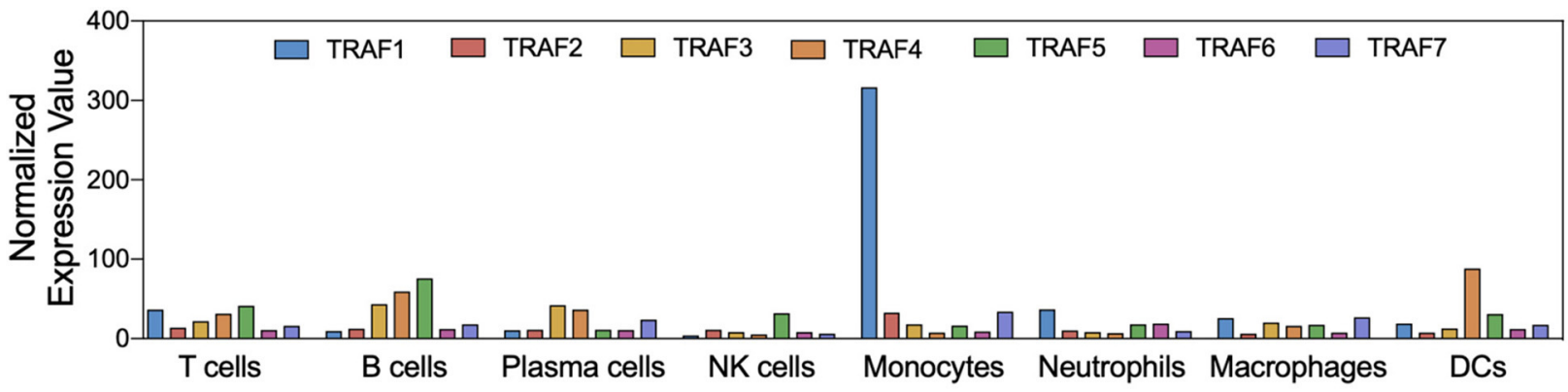

B

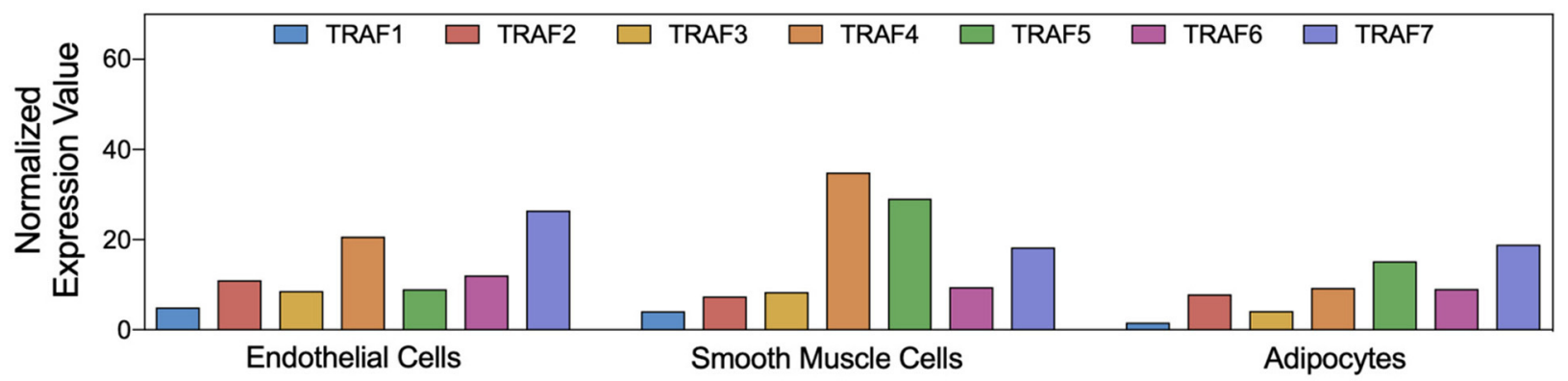

C

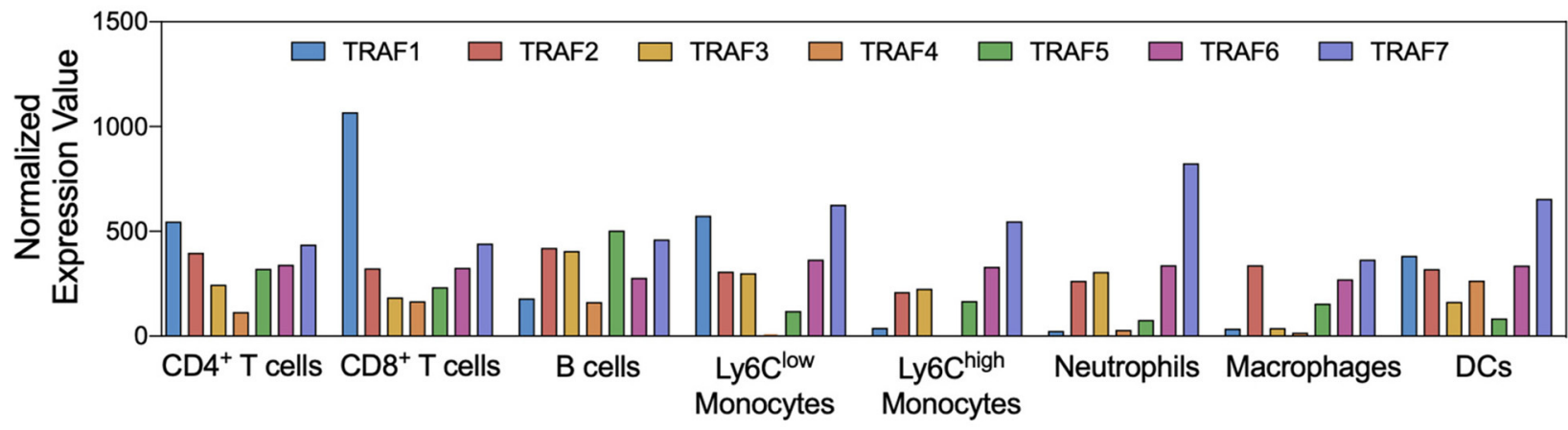

FIGURE 3 | Cell-type specific expression of TRAFs. Gene expression patterns of TRAF1-7 in atherosclerosis-relevant cell types are shown. Normalized expression values for human immune (A) and stromal (B) cell types were extracted from the Human Protein Atlas project (51), not further adjusted, and plotted as given. Normalized expression of TRAF mRNA in mouse cell types was extracted from the ImmGen database (C).

novo atherosclerosis in the absence of TRAF1 is accompanied by a lower content of macrophages and lipids in TRAF1deficient plaques, an effect likely caused by reduced VCAM1 and ICAM-1 expression on EC and reduced $\beta 1$-integrin expression on macrophages. This observation confirms previous studies that found that TRAF1 is required for the expression of ICAM-1 and chemokines in the lung (81). Bone marrow transplantation studies further indicated a requirement for TRAF1 on bone marrow-derived immune cells and stromal cells in maintaining adhesion factor expression and leukocyte recruitment to inflammatory sites (60). Notably, general immune responses seem not to be affected by a lack of TRAF1 (60), as opposed to previous findings that indicated a hyperproliferative phenotype in T cells with TRAF1-deficiency (82). In humans, expression of TRAF1 is increased in fibrous, atheromatous, and aneurysmal atherosclerotic lesions of carotid arteries (57). TRAF1 blood mRNA expression is elevated in patients with acute coronary syndrome (60). Furthermore, the rs2416804 allele in the TRAF1 gene was associated with carotid intima-media thickness, a marker for subclinical atherosclerosis that predicts subsequent clinical cardiovascular events (93). Likewise, TRAF1 promoted inflammatory pathways through an activation of the ASK1-mediated JNK/p38 pathway in a model of myocardial ischemia/reperfusion (94). Recent results, however, have questioned a mere pro-inflammatory role of TRAF1 in cardiovascular pathologies: In diet-induced obesity (DIO), TRAF1-deficient mice were protected from diet-induced weight gain and associated metabolic derangements by an increased breakdown of lipids in adipocytes and UCP1-enabled thermogenesis (59). Notably, this effect seems to be caused 


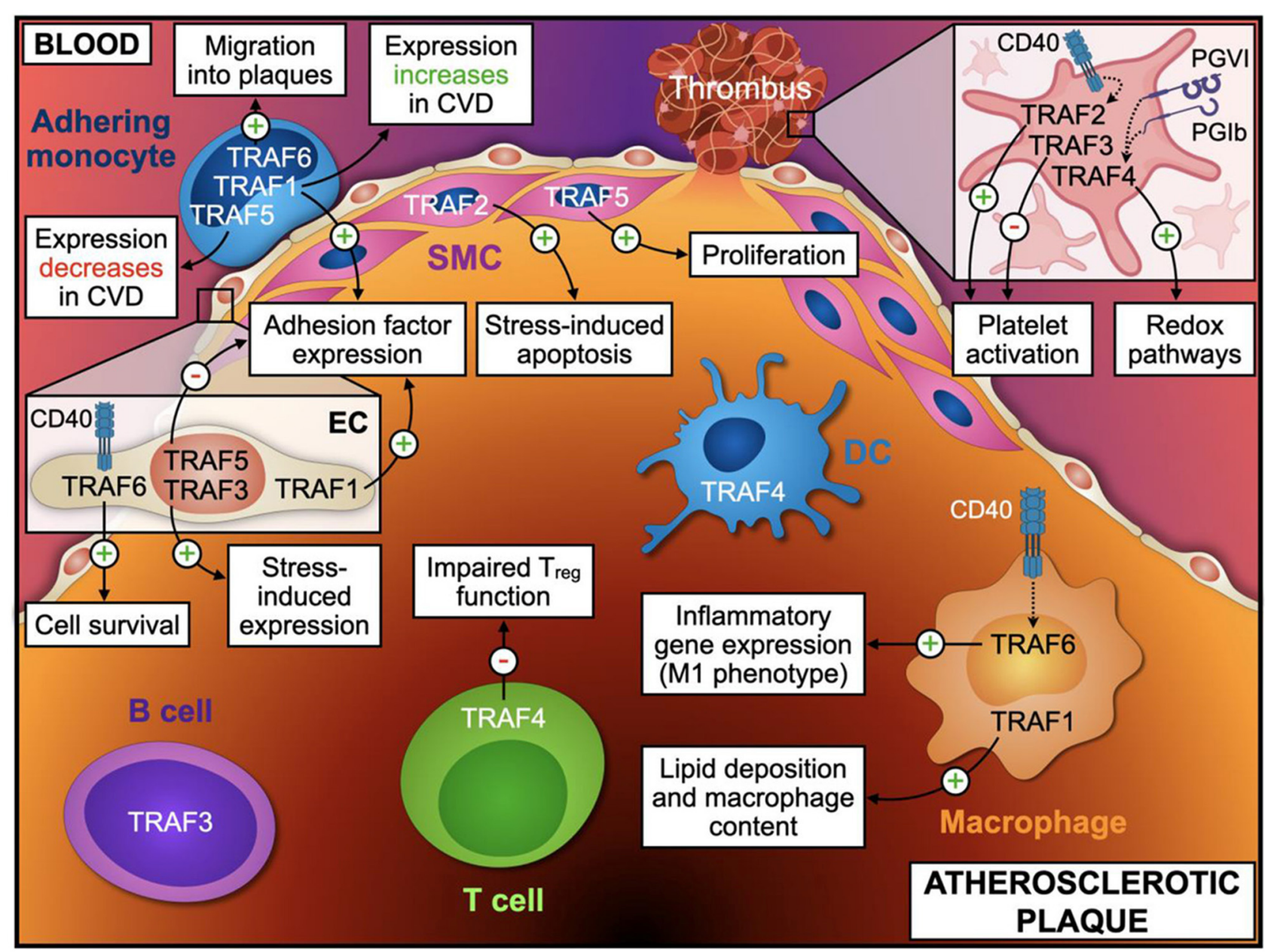

FIGURE 4 | TRAF-effector functions in atherosclerosis. Distinct cellular phenotypes and functions regulated by TRAF-associated signaling modulate vascular inflammation and atherosclerosis. The atherosclerotic plaque is separated from the blood by a thin layer of endothelial cells (EC) and smooth muscle cells (SMC). Monocytes adhere to the vascular endothelium and migrate into the plaque, where they differentiate into macrophages. Additionally, T cells, B cells, and Dendritic cells (DC) accumulate within the vessel wall and take part in regulation of local inflammatory processes. Upon rupture of the fibrotic cap, platelet activation precipitates thrombus formation and subsequent clinical complications. Only TRAFs with a proven effect or validated expression in the respective cell types are shown. Relevant TRAF-dependent processes in EC and platelets are indicated in the inlays. This figure was generated with schematics from BioRender.com.

by hyper-inflammation of adipocytes and adipose tissue, and subsequent induction of catabolic pathways. As atherosclerosis is driven by obesity and hyperlipidemia, improved metabolism in TRAF1 deficiency may contribute to its protective properties in atherosclerotic CVD, even in the light of enhanced inflammation.

\section{TRAF2}

TRAF2, a $56 \mathrm{kDa}$ protein, is ubiquitously expressed (69). TRAF2 is involved in TNFR1-, TNFR2-, Receptor Activator of NF-кB (RANK)-, OX40-, and CD40-signaling, and regulates inflammatory responses mediated by NLRs, RIG-I, and other cytokine receptors such as for IL-6R and IL-17R (44). TRAF2 binds to its receptors through the TRAF-N and TRAF-C subdomains (41). The latter also mediate binding to TRAF1 and to itself to form homodimers. The TRAF2 RING-finger domain acts as an ubiquitin ligase in the canonical pathway of NF- $\mathrm{B}$ activation, which activates IKK $\beta$ and releases NF- $\kappa \mathrm{B}$
$(95,96)$. In addition, TRAF2 mediates JNK and p38 signaling (44). These processes trigger inflammatory gene expression and promote cell survival (44). Prolonged stimulation of TNFR2 leads to the degradation of TRAF2, which also negatively regulates non-canonical NF- $\kappa$ B signaling (97). Notably, TRAF1 stabilizes TRAF2 and prevents its degradation (62). TRAF2 also contributes to NF- $\kappa \mathrm{B}$ activation after CD40 and OX40 ligation, two pro-atherogenic receptors (98-100). Although a deficiency of TRAF2 abolishes TNF- $\alpha$ signaling (101), TRAF2-deficiency results in chronic inflammation characterized by infiltration of activated $\mathrm{T}$ effector and $\mathrm{T}$ memory cells. This is caused by a dysregulation of the NF- $\kappa$ B pathway (101). TRAF2-deficiency is lethal in mice due to hyper-inflammation caused by TNF- $\alpha$ (98).

\section{Role of TRAF2 in Vascular Inflammation}

Several studies have demonstrated a crucial role of balanced TRAF2 levels in regulating $\mathrm{T}$ cell homeostasis, with either increased or decreased TRAF2 levels leading to inflammatory 
disorders (44). TRAF2 expression is elevated in murine atherosclerotic lesions and neointima after arterial injury $(57,92)$. Human atherosclerotic lesions express higher levels of TRAF2 compared to healthy carotid arteries and stable atherosclerotic lesions (53). Because TRAF2-defcient cells are highly susceptible to TNF- $\alpha$ induced-death (98), TRAF2-deficient mice show an atrophy of the thymus and the spleen and die prematurely within 14 days after birth $(101,102)$. Only one study has tested the impact of TRAF2 in experimental atherosclerosis with $\mathrm{TRAF}^{+/-}$ mice in bone marrow transplantations using TRAF2-deficient hematopoietic cells from fetal livers to generate viable mice with a deficiency of TRAF2 in hematopoietic cells (103). In these mice, atherosclerotic lesion size was similar to respective controls, suggesting that TRAF2 expressed in immune cells does not affect atherosclerosis (103). Furthermore, mice with a defective TRAF2-CD40 binding site did not show alterations in atherogenesis or in neointima formation after arterial injury $(104,105)$. The increased expression of TRAF2 in mouse and human atherosclerotic lesions could potentially be explained by the finding that porcine vascular SMC become apoptotic under mechanical stress by a TRAF2-dependent mechanism that activates the pro-apoptotic transcription factors JNK and p38 (106). Importantly, TRAF2 could contribute to plaque destabilization though the induction of SMC apoptosis. However, available data suggest that TNF-dependent anti-inflammatory properties of TRAF2 outweigh pro-inflammatory effects of TRAF2 in leukocytes and other cell types. In a murine ischemia/reperfusion model, cardiac-restricted overexpression of TRAF2 resulted in NF- $\kappa$ B activation and protection from ischemia-induced cardiomyocyte death (107). In murine DIO, hepatocyte-specific deletion of TRAF2 did not affect body weight or hepatic inflammation but attenuates the hyperglycaemic response to glucagon and protects against hyperglycaemia and hyperinsulinemia (108).

\section{TRAF3}

TRAF3 is a $65 \mathrm{kD}$ protein expressed in various cell types, including EC, SMC, fibroblasts, and immune cells (44). Among immune cells, TRAF3 expression is the highest in B cells, plasma cells, macrophages, and $\mathrm{T}$ cells. At the $\mathrm{N}$-terminal end, one RING-, five Zinc-fingers, and a leucine zipper domain mediate downstream signaling. TRAF3 inhibits CD27, CD30, CD40, OX40, and Latent Infection Membrane Protein (LMP)1 induced canonical and non-canonical NF- $\kappa \mathrm{B}$ activation mediated by TRAF2/5 (109-114), but does not interfere with transcriptional activity of TRAF6-mediated canonical NF- $\kappa$ B (115). TRAF3 induces the anti-inflammatory cytokine IL-10 after activation of IL-1/TLR-receptors (116). Consistently, mice with myeloid specific TRAF3-deficiency show decreased IL-10 and enhanced IL- 6 and IL-12 cytokine levels following an in vivo challenge by LPS. In this model, TRAF3-deficiency results in spontaneous multi-organ inflammation (117). Collectively, these findings suggest that TRAF3 is a negative regulator of the above-mentioned pathways (118). Furthermore, TRAF3 plays an important role in the homeostasis of immune cells as murine TRAF3-defcient B cells, T cells, and DCs show a prolonged survival and constitutive activation (119). Mutations in the TRAF3 gene are associated with multiple myeloma and Waldenstrom's macroglobulinemia in humans (53, 120-122). TRAF3-deficient mice are characterized by impaired leukocyte development and die prematurely, likely caused by a permanent activation of non-canonical NF- $\kappa$ B signaling (123).

\section{Role of TRAF3 in Vascular Inflammation}

Previous studies pointed out anti-inflammatory characteristics of TRAF3 in vascular biology. Laminar blood flow, an atheroprotective stimulus, induces TRAF3 expression and inhibits CD40-induced endothelial activation and cytokine production (124). In EC from human atherosclerotic plaques, TRAF3 expression is upregulated in areas with high shear stress and downregulated in areas of turbulent blood flow (125). Overexpression of TRAF3 in EC inhibits endothelial expression of proinflammatory cytokines and tissue factor, blocks DNAbinding activity of the transcription factor AP-1, and prevents CD40-induced endothelial activation (125), a known driver of atherogenesis (126). Silencing TRAF3 expression by small interference RNA (siRNA) in EC increases CD40L-induced cytokine production (53). In addition, TRAF3 expression is upregulated in mice after arterial injury, as well as in murine and human atherosclerotic lesions $(57,92)$. These data suggest an overall anti-inflammatory role of TRAF3 in vascular inflammation. The fact that TRAF3 expression is elevated in human atherosclerotic lesions (53) may be explained by a compensatory regulation. Interestingly, epigenetic regulation of TRAF3 is associated with vascular recurrence in patients with ischemic stroke (127). Due to the limited viability of TRAF3-/mice, an in vivo atherosclerosis study is missing (128). In cardiac ischemia/reperfusion injury, a knock-down of TRAF3 attenuates infarct size and inflammation by inhibition of $\mathrm{NF}-\kappa \mathrm{B}$ and xanthine oxidase $(\mathrm{XO})$ signaling pathways and restraining JNK activation (129). In mouse models of high fat diet-induced and genetic obesity, hepatocyte-specific TRAF3 deficiency decreases insulin resistance, hepatic steatosis, and expression of proinflammatory cytokines in the liver, while development of obesity per se is not altered. These data imply that hepatic TRAF3 has anti-inflammatory properties in the setting of metabolic syndrome (130).

\section{TRAF4}

Unlike other members of the TRAF family, TRAF4 is mostly involved in morphogenic and developmental processes (131). A loss of TRAF4 results in upper respiratory tract deformities and is required for myelin homeostasis in the central nervous system (132). TRAF4 is expressed ubiquitously, but mainly found in thymus, spleen, and lymph nodes. Among leukocytes, B cells, T cells, and DCs express highest TRAF4 levels. Furthermore, TRAF4 is highly expressed in human breast cancer $(133,134)$. Apart from its stimulating role in DCs migration, TRAF4 does not affect immune cell development (135). In immune cells, TRAF4 increases NF-кB signaling after ligation of the $\mathrm{T}$ regulatory $\left(\mathrm{T}_{\mathrm{reg}}\right)$ cell expressed "Glucorticoid Induced TNF-receptor" (GITR), which results in an impairment of $\mathrm{T}_{\text {reg }}$ function (136). Both, GITR (137) and $\mathrm{T}_{\text {reg }}$ cells (5), have established atheroprotective roles. The role of TRAF4 in 
TNFR signaling remains unclear, despite a weak association to Lymphotoxin beta Receptor (LT $\beta \mathrm{R}$ ) and the nerve growth factor p75 (138). In inflammatory diseases, TRAF4 has been described to exert both, adverse and protective functions: After IL-25/IL-25R ligation, TRAF4 facilitates the Act1/25R interaction and degrades the IL-25R inhibitory molecule DAZAP2, which increases airway inflammation (139). In $\mathrm{T}_{\mathrm{H}} 17$ mediated autoimmune encephalomyelitis, TRAF4 restricts IL-17 induced production of GM-CSF, IL-6, CCL2, and CXCL1 (140). There is only spare information about the role of TRAF4 in atherosclerosis due to the limited viability of $\mathrm{TRAF}^{-/-}$mice (141). Unstable atherosclerotic human plaques that are prone to rupture and to give rise to thrombotic complications show increased expression of TRAF4 (142). Evidence that TRAF4 is directly involved in vascular inflammation and atherosclerosis is missing.

\section{TRAF5}

The $64 \mathrm{kD}$ protein TRAF5 interacts with multiple inflammatory and atherogenic surface receptors including CD27, CD30, CD40, LMP-1, LT $\beta$ R, RANK, and OX40 (143-145). It is expressed in lymphoid tissues such as spleen and thymus, but also in epidermis, lungs (146), muscle, and adipose tissue (147). The expression of TRAF5 is highest in immune cells. Structurally, the C-terminal TRAF-domain is responsible for the associations to its receptor and other TRAFs. TRAF5 is highly similar to TRAF2 and TRAF3, and can form heterodimers with TRAF3 to facilitate their recruitment to inflammatory receptors such as CD40 (148, 149). TRAF5 has one RING- and five Zinc-finger domains at the $\mathrm{N}$-terminal end for downstream signaling and activation of JNK and NF-кB (150). Overexpression of TRAF5 in fibroblasts enhances LT $\beta$ R-dependent NF- $\kappa B$ and JNK signaling, indicating a pro-inflammatory role (143). In patients, a SNP within the TRAF5 gene is associated with rheumatoid arthritis (151). TRAF5 supports T cell immunity against $L$. monocytogenes (152) and enhances LMP-1 induced B cell responses (153). While these findings argue for an overall pro-inflammatory role, other reports have established a regulatory and anti-inflammatory function of TRAF5: TRAF5-deficient ECs show an enhanced activation of JNK after stimulation with TNF- $\alpha$ (103). While TRAF2 binding to OX40 induces NF- $\kappa \mathrm{B}$ activation, the interaction of TRAF5 with OX40 seems to have an inhibitory and regulatory role. Following ligation of OX40, a known pro-atherogenic receptor (154), with an agonistic anti-OX40 antibody, TRAF5 ${ }^{-/-} \mathrm{CD} 4^{+}$ $\mathrm{T}$ cells upregulated $\mathrm{T}_{\mathrm{H}} 2$-cytokines. The anti-inflammatory and regulatory properties of TRAF5 were further validated in a mouse model of asthma, where TRAF5-deficiency exacerbated lung inflammation by enhanced infiltration of eosinophils and an increased $\mathrm{T}_{\mathrm{H}} 2$ response (155). If and how $\mathrm{T}_{\mathrm{H}} 2$ immunity affects atherosclerosis is still under debate (5). In addition, TRAF5 limits autoimmune encephalitis in mice (156) and is protective in murine experimental colitis (157).

\section{Role of TRAF5 in Vascular Inflammation}

TRAF5 is overexpressed in human and murine atherosclerotic plaques, with a higher expression in fibrous atherosclerotic lesions from human carotid arteries compared to vulnerable lesions (57), suggesting a protective role of TRAF5. Consistently, TRAF5-deficient mice present with increased atherosclerosis, an effect likely caused by enhanced VCAM-1-dependent leukocyte migration and enhanced expression of MCP-1 and C-X-C motif ligand 1 (CXCL1), resulting in accelerated leukocyte recruitment into atherosclerotic lesions (103). In addition, the authors of this study found increased CD36-dependent foam cell formation and detected lower numbers of atheroprotective $\mathrm{T}_{\text {reg }}$ cells (103). While it has been proposed that TRAF5 can be partially compensated by TRAF2 (158), a deficiency of TRAF5 in bone-marrow derived cells did not affect atherosclerosis in $\mathrm{LDLR}^{-/-}$mice (103), rendering effects on lipid deposition and lower numbers of $\mathrm{T}_{\text {reg }}$ cells in plaques as indirect effects. An overall anti-atherogenic role of TRAF5 is supported by the fact that TRAF5 mRNA expression is decreased in patients with stable coronary heart disease compared to healthy individuals (103). In another study, the lack of the TRAF2, TRAF3, and TRAF5 binding site on CD40 in $\mathrm{MHCII}^{+}$cells did not interfere with neointima formation after arterial injury and atherosclerosis $(104,105)$. However, in another report, the lack of TRAF5 protected from neointima formation and vascular SMC proliferation (159). In myocardial ischemia/reperfusion injury, TRAF5 protects against inflammation and associated cardiomyocyte damage via AKT signaling (160). Recently, we have shown that a genetic deficiency of TRAF5 in mice aggravates DIO and its metabolic derangements by a proinflammatory response in adipocytes, pointing toward an anti-inflammatory role of TRAF5 in cardiometabolic disease (147). Down the same line, other reports found that CD40TRAF2/3/5 signaling in $\mathrm{MHCII}^{+}$cells protects against adipose tissue inflammation and metabolic complications associated with obesity $(161,162)$. Thus, TRAF5 signaling seems to exert an overall anti-inflammatory effect. TRAF5 reduces atherosclerosis and improves cardiometabolic risk factors. Interestingly, TRAF5 is downregulated during aging (163). Restoring or boosting TRAF5 function may therefore represent a promising therapeutic approach in cardiovascular disease.

\section{TRAF6}

TRAF6, a $63 \mathrm{kD}$ protein, is involved in multiple NF- $\mathrm{B}$ dependent processes and mediates signaling of the TNFR superfamily members, such as of CD40 and RANK, and members of the IL-1/TLR superfamily $(146,164)$. TRAF6 was first described as a signaling intermediate of IL-1R and CD40 (164). In addition, TRAF6 seems to be important for signal transduction of IL-17 and IL-25 receptors $(165,166)$. Overexpression of TRAF6 leads to p38- and JNK-activation by an interaction with TRAF2 (167). TRAF6-deficient mice show severe defects in organogenesis, lack secondary lymphoid organs, have thymic atrophy, and are characterized by decreased numbers of $\mathrm{T}_{\text {reg }}$ cells and exaggerated inflammatory cell accumulation in most organs $(40,168)$. CD40 receptor exhibits two distinguished cytoplasmic TRAF-binding sites: a proximal binding site for TRAF6 and a distal binding site for TRAF2, TRAF3, and TRAF5 (169). TRAF6 and TRAF2/3/5 cooperate in the differentiation of B cells (170), while CD40-TRAF6 signaling seemed to be relatively more important in inducing inflammation in a model 
of murine autoimmune encephalitis (171). A lack of CD40TRAF6 binding abrogated NF- $\mathrm{KB}$, JNK, and p38 activation, and blunted inflammatory cytokine production after CD40 activation in monocytes and macrophages (172).

\section{Role of TRAF6 in Vascular Inflammation}

Among all TRAFs, TRAF6 has the highest relative expression in human arterial tissue (57), a finding consistent in murine atherosclerotic lesions (57). This modulation seems to be sitespecific, since mRNA expression of TRAF6 remains unchanged in blood of patients with or without coronary heart disease (173). TRAF6 deficiency of hematopoietic cells does neither change the size of atherosclerotic plaques in mice nor alters plaque composition (173). This sparked the idea that distinct proand anti-inflammatory TRAF6-dependent signaling pathways with a net zero effect would exist. Interestingly, a selective lack of the CD40-TRAF6 binding site, as tested with a chimeric CD40 transgene carrying specific mutations within the TRAF6 binding site in $\mathrm{MHCII}^{+}$monocytes, macrophages, dendritic cells, and B cells (171), reduced neointima formation after carotid arterial injury, whereas the TRAF2/3/5 binding did not affect neointima formation in mice $(92,104)$. The CD40TRAF6 axis also contributes to atherosclerosis by an activation of mononuclear cells, whereas CD40-TRAF2/3/5 interactions are crucial in CD40-driven immunity in other cell types, including B cells (174). Mice with a defective TRAF6 binding site on CD40 develop smaller atherosclerotic lesions compared to wildtype and CD40-TRAF2/3/5 deficient mice (105). Mice with a defective CD40-TRAF6 binding site also show reduced numbers of Ly $6 \mathrm{G}^{\text {high }}$ monocytes in peripheral blood, a reduced migration of monocytes to the arterial wall, and increased levels of antiinflammatory M2-macrophages. This overall atheroprotective phenotype coincides with a higher content of collagen and SMC in atherosclerotic plaques, which resembles a more stable plaque phenotype in humans $(105,175)$. Beyond this MHCIIrestricted effect, endothelial TRAF6-deficiency protects from atherosclerosis in female ApoE-deficient mice by inhibiting NF$\kappa \mathrm{B}$-dependent proinflammatory gene expression and monocyte adhesion to EC (176). Likewise, murine ECs deficient for TRAF6 display a markedly reduced expression of VCAM1, ICAM-1, E-selection, MCP-1, and MCP-3 levels after stimulation with oxLDL. Contrastingly, myeloid cell-specific TRAF6-deficiency caused exacerbated atherosclerosis with larger plaques containing more necrotic areas in both in male and female ApoE-deficient mice (176). ApoA-I, the core protein of high-density lipoprotein (HDL) cholesterol suppresses CD40 signaling in macrophages, by preventing TRAF6 translocation to lipid rafts through ABCA1-dependent regulation of free cholesterol efflux, which may present a novel mechanism of ApoA-I-mediated suppression of inflammation in macrophages (177). In vascular SMCs, TRAF6 induces SM22 $\beta$ ubiquitination, which maintains survival through increased G6PD activity and $\mathrm{NADP}^{+}$production (178). Thereby, TRAF6 participates in the regulation of glucose homeostasis during vascular repair after injury (178).

In summary, a growing body of evidence demonstrates a significant involvement of TRAF6-signaling in the pathogenesis of atherosclerotic CVD. Partially opposing results may well be explained by the distinct and cell-type specific expression of TRAF6-associated upstream receptors, i.e., mostly CD40associated TRAF signaling has been demonstrated to exacerbate inflammation. In this context, the specific targeting of CD40-TRAF6 interactions remains highly desirable. It is noteworthy to mention that a selective blocker of the interaction between CD40 and TRAF6 ("TRAF-STOPs") that does not affect CD40-TRAF2/3/5 interactions and preserves CD40mediated immunity reduces atherosclerosis, likely by impairing inflammatory leukocyte recruitment (39). In murine obesity, coinhibitory suppression of $\mathrm{T}$ cell activation by CD40 protects against obesity and adipose tissue inflammation, while CD40deficient mice display an aggravated phenotype during DIO (27). While a genetic deficiency of CD40-TRAF2/3/5 signaling aggravates obesity and promotes metabolic dysfunction and hepatic steatosis, mice lacking the CD40-TRAF6 binding site are protected from obesity-associated complications, arguing for opposite roles of CD40-TRAF2/3/5 and CD40-TRAF6 signaling in obesity-associated metabolic dysregulation. Notably, pharmacologic inhibition of the CD40-TRAF6 pathway ameliorates obesity-related metabolic complications (161).

\section{TRAF7}

TRAF7, a $74 \mathrm{kDa}$ protein, was originally described as a positive regulator of the stress-induced transcription factors AP-1 and CHOP (179). In contrast to other TRAFs, TRAF7 lacks the TRAF-domain and contains seven WD40-repeats at the Cterminal end followed by a RING-finger domain, potentially implying that it evolved separately (40). Expression of TRAF7 is found ubiquitously but relatively higher in the heart, spleen, kidney, liver, colon, skeletal muscle, and placenta $(179,180)$. Clinically, a TRAF7 mutation causes defects in the heart, intellectual disability, and facial defects (181). TRAF7-dependent p38 and JNK activation contributes to cellular apoptosis, while an overexpression of TRAF7 does not induce activation of NFкВ (38). siRNA targeting TRAF7 show inhibitory and agonistic effects on NF- $\mathrm{KB}$ activation depending on the cellular model. TLR2-dependent NF- $\kappa B$ activation is promoted by TRAF6 and TRAF7 (182). Because TLR2 is known to promote atherosclerosis (183), it may be speculated that TRAF7 inhibition impairs atherogenesis. However, no human or in vivo animal data addressing the role of TRAF7 in inflammatory or vascular disease have been published to date.

\section{TRAFS IN PLATELET FUNCTION AND HOMEOSTASIS}

Beyond their known role in homeostasis, platelets have been proposed to contribute to acute and chronic inflammatory pathologies, including atherosclerosis and atherothrombosis in the later stages of the disease $(184,185)$. Key mechanism of platelets that promote inflammation include the adhesion to the injured endothelium, leukocyte activation, and the formation of leukocyte-platelet aggregates (186). It has also been recognized 
that platelets have an active secretome, allowing either rapid secretion of pre-formed soluble mediators or de novo synthesis upon platelet activation. Major platelet-derived factors are proinflammatory, such as RANTES, CXCL4, IL-1 $\beta$, or CD40L (187). TRAF-associated receptors, such as CD40 and TLRs, have been detected on platelets $(188,189)$. Ligation of platelet CD40 by CD40L induced platelet activation by yet not clarified downstream signaling pathways (190) that may also involve TRAFs. Notably, expression of TRAFs in megakaryocytesthe bone marrow derived precursors of circulating plateletswas demonstrated by different studies $(53,56)$. Consistently, platelets express several TRAF members, including TRAF1, TRAF2, TRAF3, TRAF4, and TRAF6 (191). TRAF4 has been identified as a novel binding site for the platelet glycoproteins GPVI and GP1 $\beta$ (58). It has been proposed that engagement of both glycoproteins during platelet adhesion and binding of TRAF4 to their cytoplasmic tail provides a functional link to TRAF4-related downstream effector functions, such as activation of NADPH-related redox pathways (192). Whether TRAFs can be expressed at later stages of platelet differentiation is not clarified yet. It has been shown that soluble CD40L potentiates platelet activation and aggregation through a TRAF2/Rac1/p38 MAPK signaling pathway (193), while TRAF3 was demonstrated to play a negative role in regulating platelet activation (194). Mice with a genetic inhibition of CD40-TRAF6 signaling did not show altered platelet deposition and thrombus formation in an in vitro flow chamber assay, suggesting no functional role for TRAF6 in platelet function (195). These data unveil that some TRAFs directly affect platelet function and thereby provide direct signaling links between atherosclerosis and atherothrombosis. However, future studies are required to understand the participation of the TRAF family members in regulation of platelets primary functional repertoire.

\section{CONCLUSION AND THERAPEUTIC PERSPECTIVE}

TRAFs are potent regulators of several pro-inflammatory and pro-atherogenic signaling pathways (Figure 4), including these initiated by TNF-, IL-1-, IL-6-, IL-17-, and TLRsignaling. Its fundamental role in regulating these signaling cascades in either a pro- or anti-atherosclerotic fashion makes the TRAF family an attractive target for the treatment of atherosclerosis and its complications including myocardial infarction and ischemic stroke. Traditional anti-inflammatory therapies aim for the disruption of one inflammatory signaling cascade, either of soluble ligands or receptors by monoclonal antibodies or small molecule inhibitors, which is exemplified by monoclonal antibodies inhibiting IL-1 $\beta$ (11) or IL-6 (12). Moreover, broad anti-inflammatory therapy with low-dose colchicine has substantiated the role of anti-inflammatory treatments (18). However, these therapies are at the potential risk of side-effects, e.g., of an impairments of host-defense, compensatory up-regulation of other inflammatory pathways, and relapsed inflammation after discontinuation (196, 197). TRAF-directed therapies may be designed to specifically promote or inhibit downstream receptor signaling events. Such therapies may overcome some of the limitations of conventional anti-inflammatory therapies, but raise important considerations as well: First, TRAFs show a highly complex interplay with distinct downstream signaling cascades and associated upstream receptors with partially opposing and overlapping functions. TRAFs complex with other TRAFs and thereby inhibit or augment signaling capacities. Second, this complexity seems to be determined by the levels of cellular expression, concomitant signaling events, and the context of the disease. Third, numerous animal experiments highlight that unspecific neutralization of TRAFs, e.g., in genetic knockouts, may cause lethal complications and drives unconventional, often unforeseeable signaling events. These conclusions argue for a more careful evaluation of TRAFs in the context of inflammatory disease. However, recent studies have shown that TRAFs can potently limit atherosclerotic and vascular disease. Their broad action on different cell types, stromal, and bonemarrow derived cells, may be of advantage in the multifactorial and multi-cell type pathogenesis of atherosclerosis. At present, most promising targets for an anti-atherosclerotic therapy are TRAF1, TRAF5, and the CD40-TRAF6 axis as suggested by preclinical mouse models: TRAF1 acts as a proinflammatory, atherosclerosis-promoting factor, while TRAF5 serves as an atheroprotective factor; the inhibition of the CD40-TRAF6 axis attenuates atherosclerosis and neointima formation by limiting accumulation of inflammatory monocytes at sites of inflammation. These TRAFs have also demonstrated powerful effects on associated cardiometabolic conditions, such as hepatic steatosis, adipose tissue inflammation, and insulin resistance, which may in part explain atheroprotective effects. The development of small molecule inhibitors that specifically target receptor-TRAF interactions (TRAFs-STOP) demonstrates the feasibility of specific pharmacological compounds to modify TRAF function in vivo. However, other TRAFs and their functions remain potentially relevant in vascular biology: TRAF2 induces apoptosis of vascular SMC and promotes plaque destabilization, but lesion size is not affected by TRAF2-deficiency on hematopoietic cells. TRAF3 has some atheroprotective properties, but an in vivo mouse study is missing due to the limited viability of TRAF3-deficient mice. To date, there is only little evidence that TRAF4 and TRAF7 influence atherosclerosis, which calls for future investigations. Besides the development of novel, likely cell-type specific TRAF-modulators, it will also be necessary to interrogate the role of TRAFs in atherosclerosis-associated cell types and organs, such as in the bone marrow and platelets. The regulation of TRAFs in human cells, tissues, and disease models represents another important gap of knowledge. Addressing these challenges could result in the clinical development of TRAF-based inhibition of inflammation in future.

\section{AUTHOR CONTRIBUTIONS}

All authors listed have made a substantial, direct, and intellectual contribution to the work and approved it for publication. 


\section{FUNDING}

This study was funded by the Deutsche Forschungsgemeinschaft (DFG, German Research Foundation), SFB1425, project \#422681845. This project has received funding from the European Research Council (ERC) under the European

\section{REFERENCES}

1. Libby P. The changing landscape of atherosclerosis. Nature. (2021) 592:52433. doi: 10.1038/s41586-021-03392-8

2. White SJ, Newby AC, Johnson TW. Endothelial erosion of plaques as a substrate for coronary thrombosis. Thromb Haemost. (2016) 115:50919. doi: 10.1160/th15-09-0765

3. Ralston J, Nugent R. Toward a broader response to cardiometabolic disease. Nat Med. (2019) 25:1644-6. doi: 10.1038/s41591-0190642-9

4. Roth GA, Mensah GA, Johnson CO, Addolorato G, Ammirati E, Baddour LM, et al. Global burden of cardiovascular diseases and risk factors, 19902019: update from the GBD 2019 study. J Am Coll Cardiol. (2020) 76:29823021. doi: 10.1016/j.jacc.2020.11.010

5. Wolf D, Ley K. Immunity and inflammation in atherosclerosis. Circ Res. (2019) 124:315-27. doi: 10.1161/CIRCRESAHA.118.313591

6. Marchini T, Hansen S, Wolf D. ApoB-specific CD4(+) T cells in mouse and human atherosclerosis. Cells. (2021) 10:446. doi: 10.3390/cells1002 0446

7. Wolf D, Gerhardt T, Winkels H, Michel NA, Pramod AB, Ghosheh Y, et al. Pathogenic autoimmunity in atherosclerosis evolves from initially protective apolipoprotein B100-reactive CD4(+) T-regulatory cells. Circulation. (2020) 142:1279-93. doi: 10.1161/CIRCULATIONAHA.119.042863

8. Marchini T, Mitre LS, Wolf D. Inflammatory cell recruitment in cardiovascular disease. Front Cell Dev Biol. (2021) 9:635527. doi: 10.3389/fcell.2021.635527

9. Wolf D, Zirlik A, Ley K. Beyond vascular inflammation-recent advances in understanding atherosclerosis. Cell Mol Life Sci. (2015) 72:385369. doi: 10.1007/s00018-015-1971-6

10. Libby P. Inflammation in atherosclerosis. Nature. (2002) 420:86874. doi: $10.1038 /$ nature 01323

11. Ridker PM, Everett BM, Thuren T, MacFadyen JG, Chang WH, Ballantyne $\mathrm{C}$, et al. Antiinflammatory therapy with canakinumab for atherosclerotic disease. N Engl J Med. (2017) 377:1119-31. doi: 10.1056/NEJMoa1707914

12. Ridker PM, Devalaraja M, Baeres FMM, Engelmann MDM, Hovingh GK, Ivkovic M, et al. IL-6 inhibition with ziltivekimab in patients at high atherosclerotic risk (RESCUE): a doubleblind, randomised, placebo-controlled, phase 2 trial. Lancet. (2021) 397:2060-9. doi: 10.1016/S0140-6736(21)00520-1

13. Nidorf SM, Fiolet ATL, Mosterd A, Eikelboom JW, Schut A, Opstal TSJ, et al. Colchicine in patients with chronic coronary disease. N Engl J Med. (2020) 383:1838-47. doi: 10.1056/NEJMoa2021372

14. Tardif JC, Kouz S, Waters DD, Bertrand OF, Diaz R, Maggioni AP, et al. Efficacy and safety of low-dose colchicine after myocardial infarction. N Engl J Med. (2019) 381:2497-505. doi: 10.1056/NEJMoa1912388

15. Ait-Oufella H, Libby P, Tedgui A. Anticytokine immune therapy and atherothrombotic cardiovascular risk. Arterioscler Thromb Vasc Biol. (2019) 39:1510-9. doi: 10.1161/ATVBAHA.119.311998

16. Zhao Q, Hong D, Zhang Y, Sang Y, Yang Z, Zhang X. Association between anti-TNF therapy for rheumatoid arthritis and hypertension: a meta-analysis of randomized controlled trials. Medicine. (2015) 94:e731. doi: 10.1097/MD.0000000000000731

17. Hemkens LG, Ewald H, Gloy VL, Arpagaus A, Olu KK, Nidorf M, et al. Colchicine for prevention of cardiovascular events. Cochrane Database Syst Rev. (2016) 2016:CD011047. doi: 10.1002/14651858.CD011047.pub2

18. Kraler S, Wenzl FA, Luscher TF. Repurposing colchicine to combat residual cardiovascular risk: the LoDoCo2 trial. Eur J Clin Invest. (2020) 50:e13424. doi: 10.1111/eci.13424
Union's Horizon 2020 research and innovation program (grant agreement No 853425). MCG was funded by the IMM-PACT-Programme for Clinician Scientists, Department of Medicine II, Medical Center - University of Freiburg and Faculty of Medicine, University of Freiburg, funded by the DFG - 413517907.

19. Soehnlein O, Libby P. Targeting inflammation in atherosclerosis - from experimental insights to the clinic. Nat Rev Drug Discov. (2021) 20:589610. doi: 10.1038/s41573-021-00198-1

20. Packard RR, Libby P. Inflammation in atherosclerosis: from vascular biology to biomarker discovery and risk prediction. Clin Chem. (2008) 54:2438. doi: 10.1373/clinchem.2007.097360

21. Ait-Oufella H, Taleb S, Mallat Z, Tedgui A. Recent advances on the role of cytokines in atherosclerosis. Arterioscler Thromb Vasc Biol. (2011) 31:96979. doi: 10.1161/ATVBAHA.110.207415

22. Kany S, Vollrath JT, Relja B. Cytokines in inflammatory disease. Int J Mol Sci. (2019) 20:6008. doi: 10.3390/ijms20236008

23. Michel NA, Zirlik A, Wolf D. CD40L and its receptors in atherothrombosisan update. Front Cardiovasc Med. (2017) 4:40. doi: 10.3389/fcvm.2017.00040

24. Libby P. Interleukin-1 beta as a target for atherosclerosis therapy: biological basis of CANTOS and beyond. J Am Coll Cardiol. (2017) 70:227889. doi: 10.1016/j.jacc.2017.09.028

25. Kavurma MM, Tan NY, Bennett MR. Death receptors and their ligands in atherosclerosis. Arterioscler Thromb Vasc Biol. (2008) 28:1694702. doi: 10.1161/ATVBAHA.107.155143

26. Wolf D, Jehle F, Rodriguez AO, Dufner B, Hoppe N, Colberg C, et al. CD40L deficiency attenuates diet-induced adipose tissue inflammation by impairing immune cell accumulation and production of pathogenic IgG-antibodies. PLoS ONE. (2012) 7:e33026. doi: 10.1371/journal.pone.0033026

27. Wolf D, Jehle F, Anto Michel N, Bukosza EN, Rivera J, Chen YC, et al. CoInhibitory suppression of $\mathrm{T}$ cell activation by CD40 protects from obesity and adipose tissue inflammation in mice. Circulation. (2014) 129:241425. doi: 10.1161/CIRCULATIONAHA.113.008055

28. Mach F, Schonbeck U, Sukhova GK, Atkinson E, Libby P. Reduction of atherosclerosis in mice by inhibition of CD40 signaling. Nature. (1998) 394:200-3. doi: 10.1038/28204

29. Sidiropoulos PI, Boumpas DT. Lessons learned from anti-CD40L treatment in systemic lupus erythematosus patients. Lupus. (2004) 13:391-7. doi: 10.1191/0961203304lu1032oa

30. Branen L, Hovgaard L, Nitulescu M, Bengtsson E, Nilsson J, Jovinge $\mathrm{S}$. Inhibition of tumor necrosis factor-alpha reduces atherosclerosis in apolipoprotein E knockout mice. Arterioscler Thromb Vasc Biol. (2004) 24:2137-42. doi: 10.1161/01.ATV.0000143933.20616.1b

31. Murdaca G, Spano F, Contatore M, Guastalla A, Penza E, Magnani O, et al. Infection risk associated with anti-TNF-alpha agents: a review. Expert Opin Drug Saf. (2015) 14:571-82. doi: 10.1517/14740338.2015.1009036

32. Bradley JR, Pober JS. Tumor necrosis factor receptor-associated factors (TRAFs). Oncogene. (2001) 20:6482-91. doi: 10.1038/sj.onc 1204788

33. Mu Y, Sundar R, Thakur N, Ekman M, Gudey SK, Yakymovych M, et al. TRAF6 ubiquitinates TGFbeta type I receptor to promote its cleavage and nuclear translocation in cancer. Nat Commun. (2011) 2:330. doi: $10.1038 /$ ncomms 1332

34. Motegi $\mathrm{H}$, Shimo $\mathrm{Y}$, Akiyama T, Inoue J. TRAF6 negatively regulates the Jak1-Erk pathway in interleukin-2 signaling. Genes Cells. (2011) 16:17989. doi: 10.1111/j.1365-2443.2010.01474.x

35. Swaidani S, Liu C, Zhao J, Bulek K, Li X. TRAF regulation of IL-17 cytokine signaling. Front Immunol. (2019) 10:1293. doi: 10.3389/fimmu.2019.01293

36. Yang $\mathrm{CH}$, Murti A, Pfeffer SR, Fan M, Du Z, Pfeffer LM. The role of TRAF2 binding to the type I interferon receptor in alternative NF kappaB activation and antiviral response. J Biol Chem. (2008) 283:1430916. doi: 10.1074/jbc.M708895200

37. Xie YF, Cui YB, Hui XW, Wang L, Ma XL, Chen $\mathrm{H}$, et al. Interaction of IFNlambdaR1 with TRAF6 regulates NF-kappaB 
activation and IFNlambdaR1 stability. J Cell Biochem. (2012) 113:3371-9. doi: 10.1002/jcb.24213

38. Zotti T, Vito P, Stilo R. The seventh ring: exploring TRAF7 functions. J Cell Physiol. (2012) 227:1280-4. doi: 10.1002/jcp.24011

39. Seijkens TTP, van Tiel CM, Kusters PJH, Atzler D, Soehnlein O, Zarzycka B, et al. Targeting CD40-Induced TRAF6 signaling in macrophages reduces atherosclerosis. J Am Coll Cardiol. (2018) 71:527-42. doi: 10.1016/j.jacc.2017.11.055

40. So T. The immunological significance of tumor necrosis factor receptor-associated factors (TRAFs). Int Immunol. (2021) 34:7-20. doi: 10.1093/intimm/dxab058

41. Takeuchi M, Rothe M, Goeddel DV. Anatomy of TRAF2. Distinct domains for nuclear factor-kappaB activation and association with tumor necrosis factor signaling proteins. J Biol Chem. (1996) 271:1993542. doi: $10.1074 /$ jbc.271.33.19935

42. Park HH. Structure of TRAF family: current understanding of receptor recognition. Front Immunol. (2018) 9:1999. doi: 10.3389/fimmu.2018.01999

43. Chung JY, Park YC, Ye H, Wu H. All TRAFs are not created equal: common and distinct molecular mechanisms of TRAF-mediated signal transduction. J Cell Sci. (2002) 115(Pt. 4):679-88. doi: 10.1242/jcs.115.4.679

44. Lalani AI, Zhu S, Gokhale S, Jin J, Xie P. TRAF molecules in inflammation and inflammatory diseases. Curr Pharmacol Rep. (2018) 4:6490. doi: 10.1007/s40495-017-0117-y

45. Zapata JM. TNF-receptor-associated factors as targets for drug development. Expert Opin Ther Targets. (2003) 7:411-25. doi: 10.1517/14728222.7.3.411

46. Beg AA, Baltimore D. An essential role for NF-kappaB in preventing TNF-alpha-induced cell death. Science. (1996) 274:782-4. doi: 10.1126/science.274.5288.782

47. Baeuerle PA, Baltimore D. NF-kappa B: ten years after. Cell. (1996) 87:1320. doi: 10.1016/S0092-8674(00)81318-5

48. Shaulian E, Karin M. AP-1 in cell proliferation and survival. Oncogene. (2001) 20:2390-400. doi: 10.1038/sj.onc. 1204383

49. Dhillon B, Aleithan F, Abdul-Sater Z, Abdul-Sater AA. The evolving role of TRAFs in mediating inflammatory responses. Front Immunol. (2019) 10:104. doi: 10.3389/fimmu.2019.00104

50. Ross R. Atherosclerosis-an inflammatory disease. N Engl J Med. (1999) 340:115-26. doi: 10.1056/NEJM199901143400207

51. Uhlen M, Karlsson MJ, Zhong W, Tebani A, Pou C, Mikes J, et al. A genomewide transcriptomic analysis of protein-coding genes in human blood cells. Science. (2019) 366:eaax9198. doi: 10.1126/science.aax9198

52. Heng TS, Painter MW, Immunological Genome Project C. The Immunological Genome Project: networks of gene expression in immune cells. Nat Immunol. (2008) 9:1091-4. doi: 10.1038/ni1008-1091

53. Zapata JM, Krajewska M, Krajewski S, Kitada S, Welsh K, Monks $A$, et al. TNFR-associated factor family protein expression in normal tissues and lymphoid malignancies. J Immunol. (2000) 165:5084-96. doi: 10.4049/jimmunol.165.9.5084

54. Speiser DE, Lee SY, Wong B, Arron J, Santana A, Kong YY, et al. A regulatory role for TRAF1 in antigen-induced apoptosis of T cells. J Exp Med. (1997) 185:1777-83. doi: 10.1084/jem.185.10.1777

55. Kobayashi T, Walsh PT, Walsh MC, Speirs KM, Chiffoleau E, King CG, et al. TRAF6 is a critical factor for dendritic cell maturation and development. Immunity. (2003) 19:353-63. doi: 10.1016/S1074-7613(03)00230-9

56. Krajewski S, Zapata JM, Krajewska M, VanArsdale T, Shabaik A, Gascoyne $\mathrm{RD}$, et al. Immunohistochemical analysis of in vivo patterns of TRAF3 expression, a member of the TNF receptor-associated factor family. $J$ Immunol. (1997) 159:5841.

57. Zirlik A, Bavendiek U, Libby P, MacFarlane L, Gerdes N, Jagielska $\mathrm{J}$, et al. TRAF- $1,-2,-3,-5$, and -6 are induced in atherosclerotic plaques and differentially mediate proinflammatory functions of CD40L in endothelial cells. Arterioscler Thromb Vasc Biol. (2007) 27:11017. doi: 10.1161/ATVBAHA.107.140566

58. Arthur JF, Shen Y, Gardiner EE, Coleman L, Murphy D, Kenny D, et al. TNF receptor-associated factor 4 (TRAF4) is a novel binding partner of glycoprotein $\mathrm{Ib}$ and glycoprotein VI in human platelets. J Thromb Haemost. (2011) 9:163-72. doi: 10.1111/j.1538-7836.2010. 04091.x
59. Anto Michel N, Colberg C, Buscher K, Sommer B, Pramod $\mathrm{AB}$, Ehinger $\mathrm{E}$, et al. Inflammatory pathways regulated by tumor necrosis receptor-associated factor 1 protect from metabolic consequences in diet-induced obesity. Circ Res. (2018) 122:693-700. doi: 10.1161/CIRCRESAHA.117.312055

60. Missiou A, Kostlin N, Varo N, Rudolf P, Aichele P, Ernst S, et al. Tumor necrosis factor receptor-associated factor 1 (TRAF1) deficiency attenuates atherosclerosis in mice by impairing monocyte recruitment to the vessel wall. Circulation. (2010) 121:2033-44. doi: 10.1161/CIRCULATIONAHA.109.895037

61. Kraler S, Libby P, Evans PC, Akhmedov A, Schmiady MO, Reinehr M, et al. Resilience of the internal mammary artery to atherogenesis: shifting from risk to resistance to address unmet needs. Arterioscler Thromb Vasc Biol. (2021) 41:2237-51. doi: 10.1161/ATVBAHA.121.316256

62. Edilova MI, Abdul-Sater AA, Watts TH. TRAF1 signaling in human health and disease. Front Immunol. (2018) 9:2969. doi: 10.3389/fimmu.2018.02969

63. Schwenzer R, Siemienski K, Liptay S, Schubert G, Peters N, Scheurich P, et al. The human tumor necrosis factor (TNF) receptor-associated factor 1 gene (TRAF1) is up-regulated by cytokines of the TNF ligand family and modulates TNF-induced activation of NF-kappaB and c-Jun N-terminal kinase. J Biol Chem. (1999) 274:19368-74. doi: 10.1074/jbc.274.27.19368

64. Dunn IF, Sannikova TY, Geha RS, Tsitsikov EN. Identification and characterization of two CD40-inducible enhancers in the mouse TRAF1 gene locus. Mol Immunol. (2000) 37:961-73. doi: 10.1016/S0161-5890(01)00015-3

65. Hsu H, Huang J, Shu HB, Baichwal V, Goeddel DV. TNF-dependent recruitment of the protein kinase RIP to the TNF receptor-1 signaling complex. Immunity. (1996) 4:387-96. doi: 10.1016/S1074-7613(00)80252-6

66. Lee SY, Lee SY, Choi Y. TRAF-interacting protein (TRIP): a novel component of the tumor necrosis factor receptor (TNFR)- and CD30-TRAF signaling complexes that inhibits TRAF2-mediated NF-kappaB activation. J Exp Med. (1997) 185:1275-85. doi: 10.1084/jem.185.7.1275

67. Micheau O, Thome M, Schneider P, Holler N, Tschopp J, Nicholson DW, et al. The long form of FLIP is an activator of caspase- 8 at the Fas death-inducing signaling complex. J Biol Chem. (2002) 277:4516271. doi: 10.1074/jbc.M206882200

68. Zheng C, Kabaleeswaran V, Wang Y, Cheng G, Wu H. Crystal structures of the TRAF2: cIAP2 and the TRAF1: TRAF2: cIAP2 complexes: affinity, specificity, and regulation. Mol Cell. (2010) 38:10113. doi: 10.1016/j.molcel.2010.03.009

69. Rothe M, Wong SC, Henzel WJ, Goeddel DV. A novel family of putative signal transducers associated with the cytoplasmic domain of the $75 \mathrm{kDa}$ tumor necrosis factor receptor. Cell. (1994) 78:68192. doi: 10.1016/0092-8674(94)90532-0

70. Rothe M, Sarma V, Dixit VM, Goeddel DV. TRAF2-mediated activation of NF-kappa B by TNF receptor 2 and CD40. Science. (1995) 269:14247. doi: 10.1126/science.7544915

71. Xie P. TRAF molecules in cell signaling and in human diseases. J Mol Signal. (2013) 8:7. doi: 10.1186/1750-2187-8-7

72. Arron JR, Pewzner-Jung Y, Walsh MC, Kobayashi T, Choi Y. Regulation of the subcellular localization of tumor necrosis factor receptor-associated factor (TRAF) 2 by TRAF1 reveals mechanisms of TRAF2 signaling. J Exp Med. (2002) 196:923-34. doi: 10.1084/jem.20020774

73. Xie P, Hostager BS, Munroe ME, Moore CR, Bishop GA. Cooperation between TNF receptor-associated factors 1 and 2 in CD40 signaling. $J$ Immunol. (2006) 176:5388-400. doi: 10.4049/jimmunol.176.9.5388

74. Wicovsky A, Henkler F, Salzmann S, Scheurich P, Kneitz C, Wajant H. Tumor necrosis factor receptor-associated factor-1 enhances proinflammatory TNF receptor-2 signaling and modifies TNFR1-TNFR2 cooperation. Oncogene. (2009) 28:1769-81. doi: 10.1038/onc.2009.29

75. Song HY, Rothe M, Goeddel DV. The tumor necrosis factorinducible zinc finger protein A20 interacts with TRAF1/TRAF2 and inhibits NF-kappaB activation. Proc Natl Acad Sci USA. (1996) 93:6721-5. doi: 10.1073/pnas.93.13.6721

76. Fotin-Mleczek M, Henkler F, Hausser A, Glauner H, Samel D, Graness A, et al. Tumor necrosis factor receptor-associated factor (TRAF) 1 regulates CD40-induced TRAF2-mediated NF-kappaB activation. J Biol Chem. (2004) 279:677-85. doi: 10.1074/jbc.M310969200 
77. Wang CY, Mayo MW, Korneluk RG, Goeddel DV, Baldwin AS Jr. NF-kappaB antiapoptosis: induction of TRAF1 and TRAF2 and c-IAP1 and c-IAP2 to suppress caspase-8 activation. Science. (1998) 281:16803. doi: $10.1126 /$ science.281.5383.1680

78. Wang C, McPherson AJ, Jones RB, Kawamura KS, Lin GH, Lang PA, et al. Loss of the signaling adaptor TRAF1 causes CD8 $+\mathrm{T}$ cell dysregulation during human and murine chronic infection. J Exp Med. (2012) 209:7791. doi: 10.1084/jem.20110675

79. Sabbagh L, Srokowski CC, Pulle G, Snell LM, Sedgmen BJ, Liu Y, et al. A critical role for TNF receptor-associated factor 1 and Bim down-regulation in CD8 memory T cell survival. Proc Natl Acad Sci USA. (2006) 103:187038. doi: 10.1073/pnas.0602919103

80. Zhang XF, Zhang R, Huang L, Wang PX, Zhang Y, Jiang DS, et al. TRAF1 is a key mediator for hepatic ischemia/reperfusion injury. Cell Death Dis. (2014) 5:e1467. doi: 10.1038/cddis.2014.411

81. Oyoshi MK, Barthel R, Tsitsikov EN. TRAF1 regulates recruitment of lymphocytes and, to a lesser extent, neutrophils, myeloid dendritic cells and monocytes to the lung airways following lipopolysaccharide inhalation. Immunology. (2007) 120:303-14. doi: 10.1111/j.1365-2567.2006.02499.x

82. Tsitsikov EN, Laouini D, Dunn IF, Sannikova TY, Davidson L, Alt FW, et al. TRAF1 is a negative regulator of TNF signaling enhanced TNF signaling in TRAF1-deficient mice. Immunity. (2001) 15:64757. doi: 10.1016/S1074-7613(01)00207-2

83. Lavorgna A, De Filippi R, Formisano S, Leonardi A. TNF receptor-associated factor 1 is a positive regulator of the NF-kappaB alternative pathway. $\mathrm{Mol}$ Immunol. (2009) 46:3278-82. doi: 10.1016/j.molimm.2009.07.029

84. McPherson AJ, Snell LM, Mak TW, Watts TH. Opposing roles for TRAF1 in the alternative versus classical NF-kappaB pathway in T cells. J Biol Chem. (2012) 287:23010-9. doi: 10.1074/jbc.M112.350538

85. Carpentier I, Beyaert R. TRAF1 is a TNF inducible regulator of NF-kappaB activation. FEBS Lett. (1999) 460:24650. doi: 10.1016/S0014-5793(99)01356-3

86. Henkler F, Baumann B, Fotin-Mleczek M, Weingartner M, Schwenzer R, Peters N, et al. Caspase-mediated cleavage converts the tumor necrosis factor (TNF) receptor-associated factor (TRAF)-1 from a selective modulator of TNF receptor signaling to a general inhibitor of NF-kappaB activation. J Biol Chem. (2003) 278:29216-30. doi: 10.1074/jbc.M211090200

87. Abdul-Sater AA, Edilova MI, Clouthier DL, Mbanwi A, Kremmer E, Watts TH. The signaling adaptor TRAF1 negatively regulates Toll-like receptor signaling and this underlies its role in rheumatic disease. Nat Immunol. (2017) 18:26-35. doi: 10.1038/ni.3618

88. Plenge RM, Seielstad M, Padyukov L, Lee AT, Remmers EF, Ding B, et al. TRAF1-C5 as a risk locus for rheumatoid arthritis-a genomewide study. $N$ Engl J Med. (2007) 357:1199-209. doi: 10.1056/NEJMoa073491

89. Libby P. Role of inflammation in atherosclerosis associated with rheumatoid arthritis. Am J Med. (2008) 121(Suppl. 1):S21-31. doi: 10.1016/j.amjmed.2008.06.014

90. Panoulas VF, Smith JP, Nightingale P, Kitas GD. Association of the TRAF1/C5 locus with increased mortality, particularly from malignancy or sepsis, in patients with rheumatoid arthritis. Arthritis Rheum. (2009) 60:39-46. doi: 10.1002/art.24176

91. Pryhuber GS, Huyck HL, Roper JM, Cornejo J, O’Reilly MA, Pierce RH, et al. Acute tumor necrosis factor-alpha-induced liver injury in the absence of tumor necrosis factor receptor-associated factor 1 gene expression. Am J Pathol. (2005) 166:1637-45. doi: 10.1016/S0002-9440(10)62474-1

92. Song Z, Jin R, Yu S, Rivet JJ, Smyth SS, Nanda A, et al. CD40 is essential in the upregulation of TRAF proteins and NF-kappaB-dependent proinflammatory gene expression after arterial injury. PLoS ONE. (2011) 6:e23239. doi: 10.1371/journal.pone.0023239

93. Hessler N, Geisel MH, Coassin S, Erbel R, Heilmann S, Hennig $\mathrm{F}$, et al. Linkage and association analysis identifies TRAF1 influencing common carotid intima-media thickness. Stroke. (2016) 47:2904-9. doi: 10.1161/STROKEAHA.116.013943

94. Xu W, Zhang L, Zhang Y, Zhang K, Wu Y, Jin D. TRAF1 exacerbates myocardial ischemia reperfusion injury via ASK1-JNK/p38 signaling. $J$ Am Heart Assoc. (2019) 8:e012575. doi: 10.1161/JAHA.119. 012575
95. Park YC, Burkitt V, Villa AR, Tong L, Wu H. Structural basis for selfassociation and receptor recognition of human TRAF2. Nature. (1999) 398:533-8. doi: 10.1038/19110

96. Xia ZP, Chen ZJ. TRAF2: a double-edged sword? Sci STKE. (2005) 2005:pe7. doi: 10.1126/stke.2722005pe7

97. Grech AP, Amesbury M, Chan T, Gardam S, Basten A, Brink R. TRAF2 differentially regulates the canonical and noncanonical pathways of NF-kappaB activation in mature B cells. Immunity. (2004) 21:62942. doi: 10.1016/j.immuni.2004.09.011

98. Yeh WC, Shahinian A, Speiser D, Kraunus J, Billia F, Wakeham A, et al. Early lethality, functional NF-kappaB activation, and increased sensitivity to TNF-induced cell death in TRAF2-deficient mice. Immunity. (1997) 7:715-25. doi: 10.1016/S1074-7613(00)80391-X

99. Nguyen LT, Duncan GS, Mirtsos C, Ng M, Speiser DE, Shahinian A, et al. TRAF2 deficiency results in hyperactivity of certain TNFR1 signals and impairment of CD40-mediated responses. Immunity. (1999) 11:37989. doi: 10.1016/S1074-7613(00)80113-2

100. Nakano M, Fukumoto Y, Satoh K, Ito Y, Kagaya Y, Ishii N, et al. OX40 ligand plays an important role in the development of atherosclerosis through vasa vasorum neovascularization. Cardiovasc Res. (2010) 88:53946. doi: $10.1093 / \mathrm{cvr} / \mathrm{cvq} 211$

101. Lin WJ, Su YW, Lu YC, Hao Z, Chio, II, et al. Crucial role for TNF receptor-associated factor 2 (TRAF2) in regulating NFkappaB2 signaling that contributes to autoimmunity. Proc Natl Acad Sci USA. (2011) 108:183549. doi: 10.1073/pnas.1109427108

102. Chuang HC, Sheu WH, Lin YT, Tsai CY, Yang CY, Cheng YJ, et al. HGK/MAP4K4 deficiency induces TRAF2 stabilization and Th17 differentiation leading to insulin resistance. Nat Commun. (2014) 5:4602. doi: $10.1038 /$ ncomms5602

103. Missiou A, Rudolf P, Stachon P, Wolf D, Varo N, Aichele P, et al. TRAF5 deficiency accelerates atherogenesis in mice by increasing inflammatory cell recruitment and foam cell formation. Circ Res. (2010) 107:75766. doi: 10.1161/CIRCRESAHA.110.219295

104. Donners MM, Beckers L, Lievens D, Munnix I, Heemskerk J, Janssen BJ, et al. The CD40-TRAF6 axis is the key regulator of the CD40/CD40L system in neointima formation and arterial remodeling. Blood. (2008) 111:4596604. doi: 10.1182/blood-2007-05-088906

105. Lutgens E, Lievens D, Beckers L, Wijnands E, Soehnlein O, Zernecke A, et al. Deficient CD40-TRAF6 signaling in leukocytes prevents atherosclerosis by skewing the immune response toward an antiinflammatory profile. J Exp Med. (2010) 207:391-404. doi: 10.1084/jem.20091293

106. Sotoudeh M, Li YS, Yajima N, Chang CC, Tsou TC, Wang Y, et al. Induction of apoptosis in vascular smooth muscle cells by mechanical stretch. Am J Physiol Heart Circ Physiol. (2002) 282:H170916. doi: 10.1152/ajpheart.00744.2001

107. Burchfield JS, Dong J-W, Sakata Y, Gao F, Tzeng H-P, Topkara VK, et al. The cytoprotective effects of tumor necrosis factor are conveyed through tumor necrosis factor receptor-associated factor 2 in the heart. Circ Heart Fail. (2010) 3:157-64. doi: 10.1161/CIRCHEARTFAILURE.109.899732

108. Chen Z, Sheng L, Shen H, Zhao Y, Wang S, Brink R, et al. Hepatic TRAF2 regulates glucose metabolism through enhancing glucagon responses. Diabetes. (2012) 61:566-73. doi: 10.2337/db11-0474

109. Hu HM, O’Rourke K, Boguski MS, Dixit VM. A novel RING finger protein interacts with the cytoplasmic domain of CD40. J Biol Chem. (1994) 269:30069-72. doi: 10.1016/S0021-9258(18)43772-6

110. Devergne O, Hatzivassiliou E, Izumi KM, Kaye KM, Kleijnen MF, Kieff E, et al. Association of TRAF1, TRAF2, and TRAF3 with an Epstein-Barr virus LMP1 domain important for B-lymphocyte transformation: role in NF-kappaB activation. Mol Cell Biol. (1996) 16:7098-108. doi: 10.1128/MCB.16.12.7098

111. Eliopoulos AG, Dawson CW, Mosialos G, Floettmann JE, Rowe M, Armitage RJ, et al. CD40-induced growth inhibition in epithelial cells is mimicked by Epstein-Barr Virus-encoded LMP1: involvement of TRAF3 as a common mediator. Oncogene. (1996) 13:2243-54.

112. Duckett CS, Gedrich RW, Gilfillan MC, Thompson CB. Induction of nuclear factor kappaB by the CD30 receptor is mediated by TRAF1 and TRAF2. Mol Cell Biol. (1997) 17:1535-42. doi: 10.1128/MCB.17.3.1535 
113. Kawamata S, Hori T, Imura A, Takaori-Kondo A, Uchiyama T. Activation of OX40 signal transduction pathways leads to tumor necrosis factor receptorassociated factor (TRAF) 2- and TRAF5-mediated NF-kappaB activation. $J$ Biol Chem. (1998) 273:5808-14. doi: 10.1074/jbc.273.10.5808

114. Takaori-Kondo A, Hori T, Fukunaga K, Morita R, Kawamata S, Uchiyama T. Both amino- and carboxyl-terminal domains of TRAF3 negatively regulate NF-kappaB activation induced by OX40 signaling. Biochem Biophys Res Commun. (2000) 272:856-63. doi: 10.1006/bbrc.2000.2860

115. Hauer J, Püschner S, Ramakrishnan P, Simon U, Bongers M, Federle $\mathrm{C}$, et al. TNF receptor (TNFR)-associated factor (TRAF) 3 serves as an inhibitor of TRAF2/5-mediated activation of the noncanonical NF$\kappa \mathrm{B}$ pathway by TRAF-binding TNFRs. Proc Natl Acad Sci USA. (2005) 102:2874. doi: 10.1073/pnas.0500187102

116. Hacker H, Redecke V, Blagoev B, Kratchmarova I, Hsu LC, Wang GG, et al. Specificity in Toll-like receptor signaling through distinct effector functions of TRAF3 and TRAF6. Nature. (2006) 439:204-7. doi: 10.1038/nature04369

117. Lalani AI, Moore CR, Luo C, Kreider BZ, Liu Y, Morse HC, et al. Myeloid cell TRAF3 regulates immune responses and inhibits inflammation and tumor development in mice. J Immunol. (2015) 194:334-48. doi: 10.4049/jimmunol.1401548

118. Bishop GA, Stunz LL, Hostager BS. TRAF3 as a Multifaceted Regulator of B Lymphocyte Survival and Activation. Front Immunol. (2018) 9:2161. doi: 10.3389/fimmu.2018.02161

119. Xie P, Poovassery J, Stunz LL, Smith SM, Schultz ML, Carlin LE, et al. Enhanced Toll-like receptor (TLR) responses of TNFR-associated factor 3 (TRAF3)-deficient B lymphocytes. J Leukoc Biol. (2011) 90:114957. doi: 10.1189/jlb.0111044

120. Annunziata CM, Davis RE, Demchenko Y, Bellamy W, Gabrea A, Zhan F, et al. Frequent engagement of the classical and alternative NF-kappaB pathways by diverse genetic abnormalities in multiple myeloma. Cancer Cell. (2007) 12:115-30. doi: 10.1016/j.ccr.2007.07.004

121. Braggio E, Keats JJ, Leleu X, Van Wier S, Jimenez-Zepeda VH, Valdez $\mathrm{R}$, et al. Identification of copy number abnormalities and inactivating mutations in two negative regulators of nuclear factor-kappaB signaling pathways in Waldenstrom's macroglobulinemia. Cancer Res. (2009) 69:3579-88. doi: 10.1158/0008-5472.CAN-08-3701

122. Moore CR, Liu Y, Shao C, Covey LR, Morse HC, 3rd, Xie P. Specific deletion of TRAF3 in B lymphocytes leads to B-lymphoma development in mice. Leukemia. (2012) 26:1122-7. doi: 10.1038/leu.2011.309

123. He JQ, Zarnegar B, Oganesyan G, Saha SK, Yamazaki S, Doyle SE, et al. Rescue of TRAF3-null mice by p100 NF-kappa B deficiency. J Exp Med. (2006) 203:2413-8. doi: 10.1084/jem.20061166

124. Urbich C, Walter DH, Zeiher AM, Dimmeler S. Laminar shear stress upregulates integrin expression: role in endothelial cell adhesion and apoptosis. Circ Res. (2000) 87:683-9. doi: 10.1161/01.RES.87.8.683

125. Urbich C, Mallat Z, Tedgui A, Clauss M, Zeiher AM, Dimmeler S. Upregulation of TRAF-3 by shear stress blocks CD40-mediated endothelial activation. J Clin Invest. (2001) 108:1451-8. doi: 10.1172/JCI200113620

126. Gissler MC, Scherrer P, Anto Michel N, Pennig J, Hoppe N, Füner L, et al. Deficiency of endothelial CD40 induces a stable plaque phenotype and limits inflammatory cell recruitment to atherosclerotic lesions in mice. Thromb Haemost. (2021) 121:1530-40. doi: 10.1055/a-1397-1858

127. Gallego-Fabrega C, Carrera C, Reny JL, Fontana P, Slowik A, Pera $\mathrm{J}$, et al. TRAF3 Epigenetic regulation is associated with vascular recurrence in patients with ischemic stroke. Stroke. (2016) 47:11806. doi: 10.1161/STROKEAHA.115.012237

128. Xu Y, Cheng G, Baltimore D. Targeted disruption of TRAF3 leads to postnatal lethality and defective T-dependent immune responses. Immunity. (1996) 5:407-15. doi: 10.1016/S1074-7613(00)80497-5

129. Liu X, Zhang L, Qin H, Han X, Zhang Z, Zhang Z, et al. Inhibition of TRAF3 expression alleviates cardiac ischemia reperfusion (IR) injury: a mechanism involving in apoptosis, inflammation and oxidative stress. Biochem Biophys Res Commun. (2018) 506:298-305. doi: 10.1016/j.bbrc.2018.10.058

130. Chen Z, Canet MJ, Sheng L, Jiang L, Xiong Y, Yin L, et al. Hepatocyte TRAF3 promotes insulin resistance and type 2 diabetes in mice with obesity. Mol Metab. (2015) 4:951-60. doi: 10.1016/j.molmet.2015.09.013
131. Rousseau A, Rio M-C, Alpy F. TRAF4, at the crossroad between morphogenesis and cancer. Cancers. (2011) 3:273449. doi: 10.3390/cancers3022734

132. Blaise S, Kneib M, Rousseau A, Gambino F, Chenard MP, Messadeq N, et al. In vivo evidence that TRAF4 is required for central nervous system myelin homeostasis. PLoS ONE. (2012) 7:e30917. doi: 10.1371/journal.pone.0030917

133. Tomasetto C, Regnier CH, Rio MC. TRAF-4 expression in breast carcinomas. Am J Pathol. (1998) 153:2007-8. doi: 10.1016/S0002-9440(10)65714-8

134. Regnier CH, Tomasetto C, Moog-Lutz C, Chenard MP, Wendling C, Basset P, et al. Presence of a new conserved domain in CART1, a novel member of the tumor necrosis factor receptor-associated protein family, which is expressed in breast carcinoma. J Biol Chem. (1995) 270:2571521. doi: $10.1074 /$ jbc.270.43.25715

135. Cherfils-Vicini J, Vingert B, Varin A, Tartour E, Fridman WH, Sautes-Fridman C, et al. Characterization of immune functions in TRAF4-deficient mice. Immunology. (2008) 124:56274. doi: 10.1111/j.1365-2567.2008.02810.x

136. Esparza EM, Arch RH. TRAF4 functions as an intermediate of GITRinduced NF-kappaB activation. Cell Mol Life Sci. (2004) 61:308792. doi: 10.1007/s00018-004-4417-0

137. Meiler S, Smeets E, Winkels H, Shami A, Pascutti MF, Nolte MA, et al. Constitutive GITR activation reduces atherosclerosis by promoting regulatory CD4+ T-cell responses-brief report. Arterioscler Thromb Vasc Biol. (2016) 36:1748-52. doi: 10.1161/ATVBAHA.116.307354

138. Krajewska M, Krajewski S, Zapata JM, Van Arsdale T, Gascoyne RD, Berern $\mathrm{K}$, et al. TRAF-4 expression in epithelial progenitor cells. Analysis in normal adult, fetal, and tumor tissues. Am J Pathol. (1998) 152:1549-61.

139. Zepp JA, Wu L, Qian W, Ouyang W, Aronica M, Erzurum S, et al. TRAF4-SMURF2-mediated DAZAP2 degradation is critical for IL-25 signaling and allergic airway inflammation. J Immunol. (2015) 194:282637. doi: 10.4049/jimmunol.1402647

140. Zepp JA, Liu C, Qian W, Wu L, Gulen MF, Kang Z, et al. Cutting edge: TNF receptor-associated factor 4 restricts IL-17-mediated pathology and signaling processes. J Immunol. (2012) 189:33-7. doi: 10.4049/jimmunol.1200470

141. Regnier CH, Masson R, Kedinger V, Textoris J, Stoll I, Chenard MP, et al. Impaired neural tube closure, axial skeleton malformations, and tracheal ring disruption in TRAF4-deficient mice. Proc Natl Acad Sci USA. (2002) 99:5585-90. doi: 10.1073/pnas.052124799

142. Slevin M, Elasbali AB, Miguel Turu M, Krupinski J, Badimon L, Gaffney J. Identification of differential protein expression associated with development of unstable human carotid plaques. Am J Pathol. (2006) 168:100421. doi: 10.2353/ajpath.2006.050471

143. Nakano H, Oshima H, Chung W, Williams-Abbott L, Ware CF, Yagita H, et al. TRAF5, an activator of NF-kappaB and putative signal transducer for the lymphotoxin-beta receptor. J Biol Chem. (1996) 271:146614. doi: 10.1074/jbc.271.25.14661

144. Xie P, Kraus ZJ, Stunz LL, Bishop GA. Roles of TRAF molecules in B lymphocyte function. Cytokine Growth Factor Rev. (2008) 19:199207. doi: 10.1016/j.cytogfr.2008.04.002

145. Ha H, Han D, Choi Y. TRAF-mediated TNFR-family signaling. Curr Protoc Immunol. (2009) Chapter 11:Unit11 9D. doi: 10.1002/0471142735.im1109ds87

146. Ishida TK, Tojo T, Aoki T, Kobayashi N, Ohishi T, Watanabe $\mathrm{T}$, et al. TRAF5, a novel tumor necrosis factor receptor-associated factor family protein, mediates CD40 signaling. Proc Natl Acad Sci USA. (1996) 93:943742. doi: 10.1073/pnas.93.18.9437

147. Gissler MC, Anto-Michel N, Pennig J, Scherrer P, Li X, Marchini $\mathrm{T}$, et al. Genetic deficiency of TRAF5 promotes adipose tissue inflammation and aggravates diet-induced obesity in mice. Arterioscler Thromb Vasc Biol. (2021) 41:2563-74. doi: 10.1161/ATVBAHA.121. 316677

148. Pullen SS, Miller HG, Everdeen DS, Dang TT, Crute JJ, Kehry MR. CD40-tumor necrosis factor receptor-associated factor (TRAF) interactions: regulation of CD40 signaling through multiple TRAF binding sites and TRAF hetero-oligomerization. Biochemistry. (1998) 37:11836-45. doi: 10.1021/bi981067q 
149. Leo E, Welsh K, Matsuzawa S, Zapata JM, Kitada S, Mitchell RS, et al. Differential requirements for tumor necrosis factor receptorassociated factor family proteins in CD40-mediated induction of NF-kappaB and Jun N-terminal kinase activation. J Biol Chem. (1999) 274:2241422. doi: $10.1074 / \mathrm{jbc} .274 .32 .22414$

150. Hildebrand JM, Yi Z, Buchta CM, Poovassery J, Stunz LL, Bishop GA. Roles of tumor necrosis factor receptor associated factor 3 (TRAF3) and TRAF5 in immune cell functions. Immunol Rev. (2011) 244:5574. doi: 10.1111/j.1600-065X.2011.01055.x

151. Potter C, Eyre S, Cope A, Worthington J, Barton A. Investigation of association between the TRAF family genes and RA susceptibility. Ann Rheum Dis. (2007) 66:1322-6. doi: 10.1136/ard.2006.065706

152. Kraus ZJ, Haring JS, Bishop GA. TNF receptor-associated factor 5 is required for optimal $\mathrm{T}$ cell expansion and survival in response to infection. J Immunol. (2008) 181:7800-9. doi: 10.4049/jimmunol.181.11.7800

153. Kraus ZJ, Nakano H, Bishop GA. TRAF5 is a critical mediator of in vitro signals and in vivo functions of LMP1, the viral oncogenic mimic of CD40. Proc Natl Acad Sci USA. (2009) 106:17140-5. doi: 10.1073/pnas.0903786106

154. van Wanrooij EJ, van Puijvelde GH, de Vos P, Yagita H, van Berkel TJ, Kuiper J. Interruption of the Tnfrsf4/Tnfsf4 (OX40/OX40L) pathway attenuates atherogenesis in low-density lipoprotein receptor-deficient mice. Arterioscler Thromb Vasc Biol. (2007) 27:204-10. doi: 10.1161/01.ATV.0000251007.07648.81

155. So T, Salek-Ardakani S, Nakano H, Ware CF, Croft M. TNF receptorassociated factor 5 limits the induction of Th2 immune responses. J Immunol. (2004) 172:4292-7. doi: 10.4049/jimmunol.172.7.4292

156. Nagashima H, Okuyama Y, Asao A, Kawabe T, Yamaki S, Nakano H, et al. The adaptor TRAF5 limits the differentiation of inflammatory CD4(+) T cells by antagonizing signaling via the receptor for IL-6. Nat Immunol. (2014) 15:449-56. doi: 10.1038/ni.2863

157. Shang J, Li L, Wang X, Pan H, Liu S, He R, et al. Disruption of tumor necrosis factor receptor-associated factor 5 exacerbates murine experimental colitis via regulating $\mathrm{T}$ helper cell-mediated inflammation. Mediators Inflamm. (2016) 2016:9453745-. doi: 10.1155/2016/9453745

158. Tada K, Okazaki T, Sakon S, Kobarai T, Kurosawa K, Yamaoka S, et al. Critical roles of TRAF2 and TRAF5 in tumor necrosis factor-induced NFkappa B activation and protection from cell death. J Biol Chem. (2001) 276:36530-4. doi: 10.1074/jbc.M104837200

159. Willecke F, Rupprecht B, Gissler MC, Pfeiffer K, Anto-Michel N, Stachon P, et al. Tumor necrosis factor receptor-associated factor 5 promotes arterial neointima formation through smooth muscle cell proliferation. J Vasc Res. (2019) 56:308-19. doi: 10.1159/000501615

160. Xu W, Zhang L, Ma S, Zhang Y, Cai Z, Zhang K, et al. TRAF5 protects against myocardial ischemia reperfusion injury via AKT signaling. Eur J Pharmacol. (2020) 878:173092. doi: 10.1016/j.ejphar.2020.173092

161. Chatzigeorgiou A, Seijkens T, Zarzycka B, Engel D, Poggi M, van den Berg $\mathrm{S}$, et al. Blocking CD40-TRAF6 signaling is a therapeutic target in obesityassociated insulin resistance. Proc Natl Acad Sci USA. (2014) 111:268691. doi: 10.1073/pnas.1403231111

162. Gao L, Wang PX, Zhang Y, Yu CJ, Ji Y, Wang X, et al. Tumor necrosis factor receptor-associated factor 5 (Traf5) acts as an essential negative regulator of hepatic steatosis. J Hepatol. (2016) 65:125-36. doi: 10.1016/j.jhep.2016.03.006

163. Ota $M$, Nagafuchi $Y$, Hatano $H$, Ishigaki $K$, Terao $C$, Takeshima $\mathrm{Y}$, et al. Dynamic landscape of immune cell-specific gene regulation in immune-mediated diseases. Cell. (2021) 184:300621.e17. doi: 10.1016/j.cell.2021.03.056

164. Cao Z, Xiong J, Takeuchi M, Kurama T, Goeddel DV. TRAF6 is a signal transducer for interleukin-1. Nature. (1996) 383:4436. doi: $10.1038 / 383443 \mathrm{a} 0$

165. Schwandner R, Yamaguchi K, Cao Z. Requirement of tumor necrosis factor receptor-associated factor (TRAF)6 in interleukin 17 signal transduction. $J$ Exp Med. (2000) 191:1233-40. doi: 10.1084/jem.191.7.1233

166. Maezawa $\mathrm{Y}$, Nakajima $\mathrm{H}$, Suzuki $\mathrm{K}$, Tamachi T, Ikeda $\mathrm{K}$, Inoue J, et al. Involvement of TNF receptor-associated factor 6 in IL-25 receptor signaling. J Immunol. (2006) 176:1013-8. doi: 10.4049/jimmunol.176.2.1013

167. Baud V, Liu ZG, Bennett B, Suzuki N, Xia Y, Karin M. Signaling by proinflammatory cytokines: oligomerization of TRAF2 and TRAF6 is sufficient for JNK and IKK activation and target gene induction via an amino-terminal effector domain. Genes Dev. (1999) 13:1297308. doi: 10.1101/gad.13.10.1297

168. Akiyama T, Maeda S, Yamane S, Ogino K, Kasai M, Kajiura F, et al. Dependence of self-tolerance on TRAF6-directed development of thymic stroma. Science. (2005) 308:248-51. doi: 10.1126/science.1105677

169. Bishop GA, Hostager BS. Molecular mechanisms of CD40 signaling. Arch Immunol Ther Exp. (2001) 49:129-37.

170. Yasui T, Muraoka M, Takaoka-Shichijo Y, Ishida I, Takegahara N, Uchida J, et al. Dissection of B cell differentiation during primary immune responses in mice with altered CD40 signals. Int Immunol. (2002) 14:31929. doi: $10.1093 /$ intimm/14.3.319

171. Aarts SA, Seijkens TT, Kusters PJ, van Tiel CM, Reiche ME, den Toom $\mathrm{M}$, et al. Macrophage CD40 signaling drives experimental autoimmune encephalomyelitis. J Pathol. (2019) 247:471-80. doi: 10.1002/path.5205

172. Mukundan L, Bishop GA, Head KZ, Zhang L, Wahl LM, Suttles J. TNF receptor-associated factor 6 is an essential mediator of CD40-activated proinflammatory pathways in monocytes and macrophages. J Immunol. (2005) 174:1081-90. doi: 10.4049/jimmunol.174.2.1081

173. Stachon P, Missiou A, Walter C, Varo N, Colberg C, Wolf D, et al. Tumor necrosis factor receptor associated factor 6 is not required for atherogenesis in mice and does not associate with atherosclerosis in humans. PLOS ONE (2010) 5:e11589. doi: 10.1371/journal.pone.0011589

174. Elgueta R, Benson MJ, de Vries VC, Wasiuk A, Guo Y, Noelle RJ. Molecular mechanism and function of CD40/CD40L engagement in the immune system. Immunol Rev. (2009) 229:152-72. doi: 10.1111/j.1600-065X.2009.00782.x

175. Sukhova GK, Babaev VR, Sirotkin VN, Tararak E. [Phenotype changes in smooth muscle cells of human coronary arteries during aging and during development of atherosclerosis]. Kardiologiia. (1991) 31:15-9.

176. Polykratis A, van Loo G, Xanthoulea S, Hellmich M, Pasparakis M. Conditional targeting of tumor necrosis factor receptor-associated factor 6 reveals opposing functions of Toll-like receptor signaling in endothelial and myeloid cells in a mouse model of atherosclerosis. Circulation. (2012) 126:1739-51. doi: 10.1161/CIRCULATIONAHA.112.100339

177. Yin K, Chen WJ, Zhou ZG, Zhao GJ, Lv YC, Ouyang XP, et al. Apolipoprotein A-I inhibits CD40 proinflammatory signaling via ATP-binding cassette transporter A1-mediated modulation of lipid raft in macrophages. Atheroscler Thromb. (2012) 19:823-36. doi: 10.5551/jat.12823

178. Dong LH, Li L, Song Y, Duan ZL, Sun SG, Lin YL, et al. TRAF6mediated SM22alpha K21 ubiquitination promotes G6PD activation and NADPH production, contributing to GSH homeostasis and VSMC survival in vitro and in vivo. Circ Res. (2015) 117:684-94. doi: 10.1161/CIRCRESAHA.115.306233

179. Xu LG, Li LY, Shu HB. TRAF7 potentiates MEKK3-induced AP1 and CHOP activation and induces apoptosis. J Biol Chem. (2004) 279:1727882. doi: 10.1074/jbc.C400063200

180. Bouwmeester T, Bauch A, Ruffner H, Angrand PO, Bergamini G, Croughton $\mathrm{K}$, et al. A physical and functional map of the human TNFalpha/NF-kappa B signal transduction pathway. Nat Cell Biol. (2004) 6:97105. doi: $10.1038 /$ ncb1086

181. Castilla-Vallmanya L, Selmer KK, Dimartino C, Rabionet R, BlancoSanchez B, Yang S, et al. Phenotypic spectrum and transcriptomic profile associated with germline variants in TRAF7. Genet Med. (2020) 22:121526. doi: 10.1038/s41436-020-0792-7

182. Yoshida H, Jono H, Kai H, Li JD. The tumor suppressor cylindromatosis (CYLD) acts as a negative regulator for toll-like receptor 2 signaling via negative cross-talk with TRAF6 AND TRAF7. J Biol Chem. (2005) 280:41111-21. doi: 10.1074/jbc.M509526200

183. Schoneveld AH, Oude Nijhuis MM, van Middelaar B, Laman JD, de Kleijn DP, Pasterkamp G. Toll-like receptor 2 stimulation induces intimal hyperplasia and atherosclerotic lesion development. Cardiovasc Res. (2005) 66:162-9. doi: 10.1016/j.cardiores.2004.12.016

184. Gawaz M, Favaloro EJ. Platelets, inflammation and cardiovascular diseases. New concepts and therapeutic implications. Semin Thromb Hemost. (2010) 36:129-30. doi: 10.1055/s-0030-1251495

185. Huo Y, Schober A, Forlow SB, Smith DF, Hyman MC, Jung S, et al. Circulating activated platelets exacerbate atherosclerosis in mice 
deficient in apolipoprotein E. Nat Med. (2003) 9:61-7. doi: 10.1038/ $\mathrm{nm} 810$

186. Duerschmied D, Bode C, Ahrens I. Immune functions of platelets. Thromb Haemost. (2014) 112:678-91. doi: 10.1160/TH14-02-0146

187. Weyrich AS, Zimmerman GA. Platelets: signaling cells in the immune continuum. Trends Immunol. (2004) 25:489-95. doi: 10.1016/j.it.2004.07.003

188. Inwald DP, McDowall A, Peters MJ, Callard RE, Klein NJ. CD40 is constitutively expressed on platelets and provides a novel mechanism for platelet activation. Circ Res. (2003) 92:1041-8. doi: 10.1161/01.RES.0000070111.98158.6C

189. Shiraki R, Inoue N, Kawasaki S, Takei A, Kadotani M, Ohnishi Y, et al. Expression of Toll-like receptors on human platelets. Thromb Res. (2004) 113:379-85. doi: 10.1016/j.thromres.2004.03.023

190. Henn V, Steinbach S, Buchner K, Presek P, Kroczek RA. The inflammatory action of CD40 ligand (CD154) expressed on activated human platelets is temporally limited by coexpressed CD40. Blood. (2001) 98:104754. doi: 10.1182/blood.V98.4.1047

191. Cognasse F, Nguyen KA, Damien P, McNicol A, Pozzetto B, HamzehCognasse $\mathrm{H}$, et al. The inflammatory role of platelets via their TLRs and Siglec receptors. Front Immunol. (2015) 6:83. doi: 10.3389/fimmu.2015.00083

192. Wu RF, Xu YC, Ma Z, Nwariaku FE, Sarosi GA, Jr., et al. Subcellular targeting of oxidants during endothelial cell migration. J Cell Biol. (2005) 171:893-904. doi: 10.1083/jcb.2005 07004

193. Yacoub D, Hachem A, Theoret JF, Gillis MA, Mourad W, Merhi Y. Enhanced levels of soluble CD40 ligand exacerbate platelet aggregation and thrombus formation through a CD40-dependent tumor necrosis factor receptor-associated factor-2/Rac1/p38 mitogen-activated protein kinase signaling pathway. Arterioscler Thromb Vasc Biol. (2010) 30:242433. doi: 10.1161/ATVBAHA.110.216143
194. Zhang R, Zhang G, Xiang B, Chen X, Tang L, Shi S, et al. TRAF3 negatively regulates platelet activation and thrombosis. Sci Rep. (2017) 7:17112. doi: 10.1038/s41598-017-17189-1

195. Donners M, Beckers L, Noelle R, Daemen MEL. The CD40-TRAF6 axis is the key regulator of the CD40-CD40L system in neointima formation. $J$ Vasc Biol. (2005) 42(Suppl. 2):121.

196. Buckley LF, Abbate A. Interleukin-1 blockade in cardiovascular diseases: a clinical update. Eur Heart J. (2018) 39:2063-9. doi: 10.1093/eurheartj/ehy128

197. Rothman AM, Morton AC, Crossman DC, investigators M-IH Canakinumab for atherosclerotic disease. N Engl J Med. (2018) 378:197-8. doi: 10.1056/NEJMc1714635

Conflict of Interest: The authors declare that the research was conducted in the absence of any commercial or financial relationships that could be construed as a potential conflict of interest.

Publisher's Note: All claims expressed in this article are solely those of the authors and do not necessarily represent those of their affiliated organizations, or those of the publisher, the editors and the reviewers. Any product that may be evaluated in this article, or claim that may be made by its manufacturer, is not guaranteed or endorsed by the publisher.

Copyright (C) 2022 Gissler, Stachon, Wolf and Marchini. This is an open-access article distributed under the terms of the Creative Commons Attribution License (CC BY). The use, distribution or reproduction in other forums is permitted, provided the original author(s) and the copyright owner(s) are credited and that the original publication in this journal is cited, in accordance with accepted academic practice. No use, distribution or reproduction is permitted which does not comply with these terms. 